\title{
The Process of Internal Migration in England and Wales, 1851- 1911: Updating Ravenstein and the Step-Migration Hypothesis*
}

\author{
Joseph Day
}

\begin{abstract}
Since their publication in 1885 and 1889 respectively, Ravenstein's laws of migration - which have since been summarised as eleven broad rules - have achieved something approaching universal acceptance (Ravenstein 1885, 1889). While most of these laws have been tested and retested using data drawn from a range of countries and time periods - invariably reconfirming the status of his hypotheses as "laws" - one hypothesis has been resistant to attempts to confirm Ravenstein's interpretation; the so-called step-migration hypothesis. Given the conflicting definitions of step-migration, this article first recounts the historiography of the term and the subsequent reason why this paper has defined step-migration as a means by which individuals migrated, rather than a population-level phenomenon in which out-migrants are continually replaced by in-migrants. Recent studies have invariably concluded that while step-migration may have been the predominant means by which migration occurred during periods of industrialisation in the past, it is no longer the process by which movement occurs in modern, post-industrial societies (Plane et al. 2005). This article therefore critically re-evaluates the evidence upon which Ravenstein based his laws. The census. Whereas Ravenstein used the published report of the 1881 census; the present study utilises the complete, individual-level manuscript census returns from 1851 to 1911. Through an analysis of approximately 160 million lifetime migration paths, this paper draws two important conclusions. First, that most people's migratory activity tended to be concentrated in a single move - usually upon leaving home - rather than in a series of steps over their lifetimes. This means the census - recording only individuals' birthplace and location on census night - captures most people's full migration histories, amplifying its value as a source for studying migration in the past. By first identifying the age range in which migration occurred, this article argues that the similarity of the age profile of migrants to those leaving home suggests they were one-and-thesame process. By then constructing synthetic cohorts and analysing the distances migrated by the population in each census between the mean ages of key lifecycle
\end{abstract}

This article belongs to a special issue on "Internal Migration as a Driver of Regional Population Change in Europe: Updating Ravenstein". 
events - leaving home, leaving service and entering marriage - it is demonstrated that very little migration occurred beyond the first move. This is reiterated in a cohort analysis which shows very little change in the destinations of migrants between censuses. In order to search for evidence of migration post-marriage, mothers' migration paths are reconstructed from those of their co-resident children. This similarly demonstrates that only a minority of mothers migrated during their childbearing years with the majority of migration occurring prior to the birth of their first child. This article therefore shows that while 1851-1911 was not a period without migration, nor was it one of constant movement. Rather, England and Wales urbanised because the majority made a considered choice of destination once in their lives. This article therefore demonstrates that migration in steps was the exception rather than the rule and that the individual-level census returns are a valuable source of migration evidence between 1851 and 1911 and deserve far wider use.

Keywords: Step-Migration · Internal Migration · England and Wales · Nineteenth Century $\cdot$ Census

\section{Introduction}

In 1771, Joseph Shaw migrated $6 \mathrm{~km}$ to the village of Dent from his rural home in Garsdale where he was born in 1748. From there he moved to Kendal in 1776, back to Dent in 1777, before moving to Dolphinholme in 1791, to Milnthorpe in 1794 and finally to Preston in 1795 where he remained until his death in 1823. His son Benjamin on the other hand lived in the family home at Dolphinholme where he stayed until he completed his apprenticeship before meeting his future wife in Lancaster while looking for work, before settling in Preston. There is no doubt that although Joseph, who migrated in steps from the countryside to his final - urban - destination, had the more interesting migration history, this paper will argue that it was in fact Benjamin whose experience - though less interesting - was more common (Crosby 1991).

Since Ravenstein first suggested the notion that migration proceeds in steps in his seminal 1885 and 1889 papers on migration, the step-migration hypothesis has been widely accepted in the literature. Ravenstein (1885) characterised the process as when "...the inhabitants of the country immediately surrounding a town of rapid growth flock into it; the gaps thus left in the rural population are filled up by migrants from more remote districts, until the attractive force of one of our rapidly growing cities makes its influence felt, step by step, to the most remote corner of the Kingdom." However, the combined vagueness of Ravenstein's description and the heterogeneity of the data used to test it have resulted in a plethora of competing - and conflicting - definitions. Did Ravenstein mean that individuals migrated up the urban hierarchy throughout their lives or that each "step" - in-migrants filling the gaps left by out-migrants - consisted of distinct groups and that step-migration 
was a phenomenon that occurred over generations which could only be observed in the aggregate?

Grigg clearly interpreted step-migration to have been the means by which individuals migrated, describing Ravenstein's hypothesis as one in which "migrants did not proceed directly to their destination but by a series of steps" (Grigg 1977). Conversely, others have described the step-migration hypothesis as one that is more akin to chain-migration in which populations tended towards towns and cities (Champion 2019). But did Ravenstein mean that migrants simply moved nearer towns? Or that migrants moved up the urban hierarchy to progressively larger settlements? While the former - spatial stepwise migration - is generally accepted as being Ravenstein's own conception, others have argued that "hierarchical stepwise migration" where each step represents a progression up the urban hierarchy is a more useful way to conceptualise the process. However, as this latter conceptualisation removes the friction of distance inherent to Ravenstein's definition, step-migration now generally refers to moves that are both spatial and hierarchical (Conway 1980).

This however does not clarify whether the process of step-migration occurs at the level of the individual, within a single generation - intra-generational step-migration - or at a population level between generations - inter-generational stepmigration. Conway (1980) recognised that the catch-all term of "step-migration" has continued to conflate these two very different processes. In inter-generational stepmigration, individuals move from the village to a small town, their children move to larger towns and their children in turn move to cities (Hägerstrand 1957; Pryor 1969, 1975; Skeldon 1977; Harvey/Riddell 1975) At each step, the "gaps" which out-migrants left are filled by in-migrants coming from further down the urban hierarchy. Intra-generational step-migration by contrast is the process by which an individual migrates to the city from the countryside through a series of intermediate steps. In this conceptualisation, out-migrants are also replaced by in-migrants from further down the urban hierarchy and therefore, both interpretations could be consistent with Ravenstein's hypothesis as originally described.

Of the two however, inter-generational stepwise migration is the most problematic both conceptually and methodologically. Conceptually, inter-generational stepwise migration has variously been described as "replacement migration", "chain-migration", "hierarchical migration", "complex step migration" and "stage migration", all of which describe a group of out-migrants being replaced by a group of in-migrants. Conway (1980) describes this process as a "stage by stage pattern of aggregate-level migration flows through the urban hierarchy or across space towards the major urban centers [sic]". Conway makes the salient point that such a stage-by-stage progression of aggregate population flows may not be evidence of the population moving "towards" large towns and cities but rather, may simply be an artefact of an economy's spatial structure.

This is best illustrated by briefly examining the currents of migration that Ravenstein had reconstructed from the 1881 census in figure 1 and it does appear that migrants flowed in "waves" towards London for example; from Cornwall to Devon, Devon to Dorset, Dorset to Wiltshire, Wiltshire to Berkshire and Berkshire 
Fig. 1: Ravenstein's visualisation of migration flows

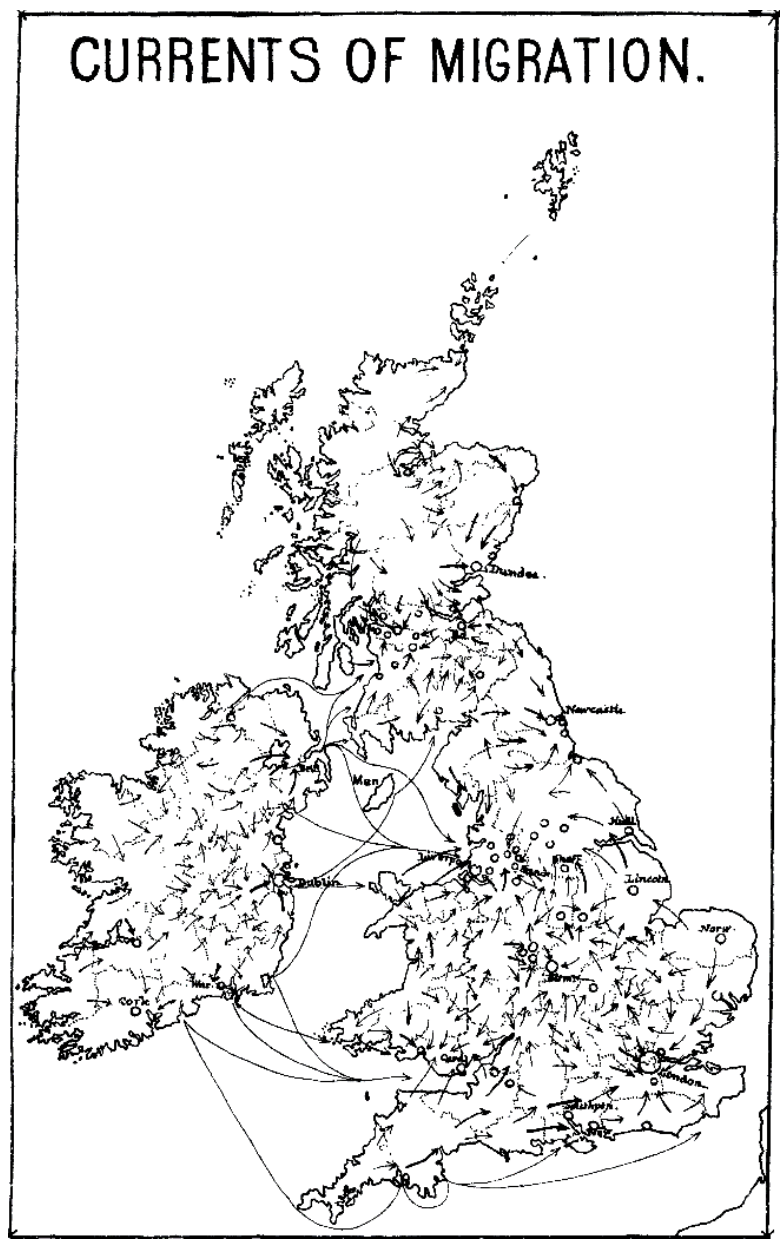

Source: Ravenstein (1885)

to London. However, while it has been argued that step-migration presents itself as flows of net migration, step-migration is by no means the only - or even the most plausible - interpretation of net migration flows (Conway 1980). For example, if - as is conceivable from figure 1 - migrants from rural south Cambridgeshire flocked to the towns of adjacent north Essex while migrants from south Essex went to neighbouring London, this would appear - in county-level flows - as step-migration. However, it is more likely that this simply reflects regional spatial economic structure if the towns of north Essex offered the best prospects to migrants from south Cambridgeshire given the perceived alternatives while London similarly represented the best opportunities to those from south Essex. The consequence is that a random spatial pattern is erroneously interpreted as one that is ordered and 
intentional (Zhao/Hahn 2014). However, potentially random patterns of net population flows could be distinguished from step-migration using longitudinal data. By record-linking migrants across censuses, the extent to which successive generations tended towards progressively larger towns could be quantified. However, as it would it be a considerable undertaking to produce a large enough sample from record-linking the nineteenth-century censuses of England and Wales to test this, this is not attempted here.

It is therefore most conceptually satisfying to interpret Ravenstein's step-migration hypothesis as the "process of human spatial behaviour in which individuals or families embark on a migration path of acculturation which gradually takes them, by way of intermediate steps, from a traditional rural environment to the modern-urban environment" (Conway 1980; Hudson 1972; Ravenstein 1885, 1889). While this article interprets step-migration as a phenomenon which occurs at the individual-level for conceptual and methodological reasons, it is not an intellectual history of the concept. Indeed, it does not intrinsically matter which definition is "correct". What matters is that multiple studies have interpreted step-migration as the process by which individuals progressively moved from the countryside to the towns and cities throughout their lifetime, and this definition has ramifications for the 1851-1911 censuses as a source of evidence for migration data (Anderson 1971; Gwynne/Sill 1976; Holderness 1970; Llewellyn-Smith 1902; Mageean/Pryce 1982; Plane et al. 2005; Pooley/D'Cruze 1994; Saville 1957; Smith 1951; Withers/Watson 1991). Indeed, as the census only recorded birthplace and location on census night, it misses any migratory "steps" that occurred in between. The census would not only then fail to accurately reconstruct individuals' migration paths, but any attempt to identify the determinants of migration between individuals' place of birth and place of residence would be artificial if no such move actually occurred. As the step-migration hypothesis casts doubt on the census as a source for patterns of migration, the hypothesis itself warrants rigorous testing (Hinde 2004).

Although previous studies, either employing the aggregated published census reports or small samples drawn from the manuscript census returns have found little evidence of the process, the step-migration hypothesis has remained a touchstone for the analysis of migration in the past (Anderson 1971; Gwynne/Sill 1976; Holderness 1970; Llewellyn-Smith 1902; Mageean/Pryce 1982; Plane et al. 2005; Pooley/D'Cruze 1994; Saville 1957; Smith 1951; Withers/Watson 1991). As Grigg (1977) noted that "nineteenth-century migration will not be properly understood until the enumerators' schedules for the century have been analysed" the present article utilises the complete, individual-level census returns for the years 1851-1861 and 1881-1911 - the 1871 returns are currently unavailable - to test the "step-bystep" hypothesis thanks to the I-CeM (Integrated Census Microdata) project (Schürer 2019).

However, that this paper finds no evidence of intra-generational step-migration has two significant implications. First, it goes against the received wisdom that stepmigration was the process by which Britain urbanised in the nineteenth century (Plane et al. 2005). Second - and perhaps more significantly - it rebuts the assertion implicit to step-migration that lifetime migration paths taken from the census fails to 
record the numerous intermediate moves which the step-migration hypothesis assumes them to have made (Hinde 2004). The argument goes that, if migrants moved several times between their place of birth and their enumerated place of residence on census night, any attempt to causally connect the determinants of migrating with the socio-economic context of the two locations would be to incorrectly imply the transfer occurred in a single move. It also assumes that the socio-economic context as reconstructed from the CEBs was an accurate reflection of the circumstances in which the move occurred, even though the move might have occurred years prior to the census being taken (Hinde 2004).

This paper demonstrates that these reservations are misplaced. The majority of the population made only a single major move in their lives upon leaving either the parental home or - in the case of males born where farm service still predominated - upon leaving service. This makes it perfectly plausible to assume that individuals' place of residence on census night is an adequate approximation of their first destination upon leaving the parental home - as proxied by their place of birth - as well as infer a causal relationship between the socio-economic contexts of an individuals' place of birth and place of enumeration on census night. Therefore, by estimating the ages at which migrants both left home and left service, it is possible to estimate the age groups that had likely only left the parental home recently prior to census night. By then analysing the extent to which the destinations of different cohorts changed over time - as well as mothers' whose migration paths are reconstructed from the birthplaces of their co-resident children - this article demonstrates that individuals' place of birth and place of enumeration on census night were most likely connected by a single move, a move which the census captures. Therefore, although this paper leaves room for the possibility that step-migration was a process of population transfers toward towns and cities at the aggregate level, it demonstrates first and foremost that it decidedly was not a phenomenon that operated at the individual-level. This paper therefore represents a step towards restoring historians' faith in the nineteenth-century censuses as a source for understanding the determinants of British urbanisation more fully.

\section{Data and methods}

By defining step-migration as the process by which individuals migrate up the urban hierarchy in short, progressive steps does at least have the advantage of making the process one that is readily identifiable, and which could exhibit itself in one of two ways. Either it will present as an increase in the proportion of the population that become resident in larger and larger settlements over time - the "hierarchical stepwise migration" - as illustrated in figure 2 in which migrants move up the urban hierarchy, with most moving to the next level, or it will present spatially as migrants move towards towns and into their commuter belts, if not necessarily into the urban settlements themselves.

Ideally, individuals would be tracked across the censuses for evidence of migration throughout their lifetimes. However, as the Integrated Census Microdata 
Fig. 2: A Ravenstein-style migration system

\section{Legend}

Width of arrows indicates relative demographic effectiveness or volumes of net migration.

\section{All Flows Up the Hierarchy \\ (No Flows Down the Hierarchy)}

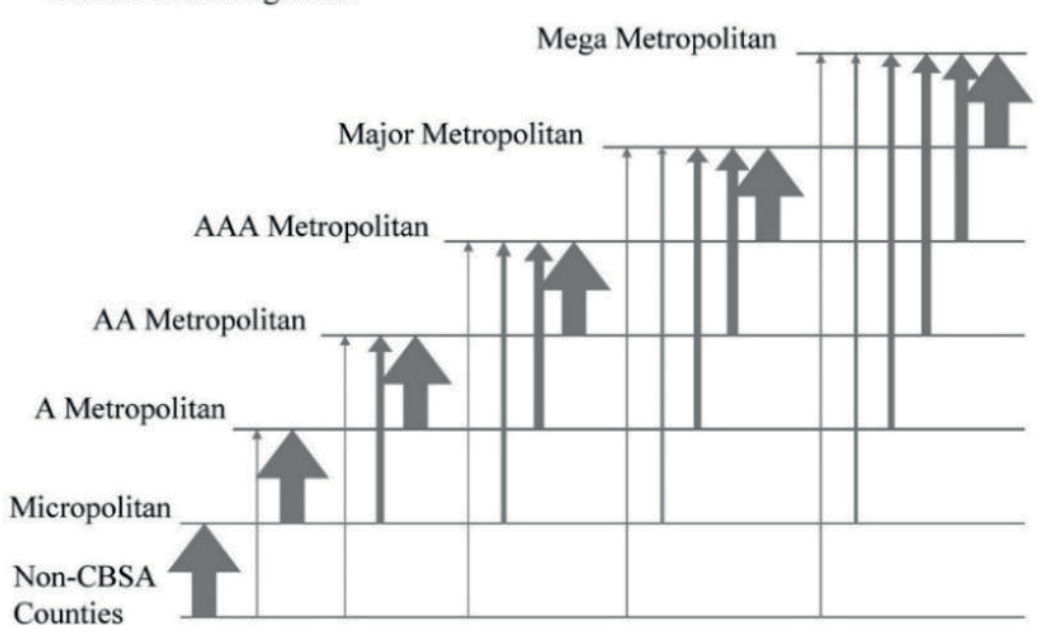

Source: Plane et al. (2005)

(I-CeM) on which this paper is based is not record-linked, the population cannot be tracked directly over time (Schürer 2019). Substituting for this, three distinct methods with which to measure step-migration are used; age-specific migration paths, cohort analysis and pseudo-longitudinal analysis. Firstly, age-specific migration produces synthetic cohorts in which the age distribution of the population is treated as if it were a single cohort passing through time. This method suggests that most migrants were not making several progressive moves up the urban hierarchy over the life-course but were instead making a single move upon leaving home or - in the male case where farm service still predominated - upon leaving service. Secondly, a cohort analysis that traces the cohort which had just left home in one census across subsequent censuses similarly demonstrates that there was very little change in the proportion that had moved "up" the urban hierarchy beyond the location they had migrated to upon leaving the parental home. Finally, a pseudo-longitudinal analysis was conducted which reconstructs the migration paths of mothers through the birthplaces of their co-resident children. This analysis again corroborates the findings of the first two methods, showing that most migratory activity occurred prior to the birth of the eldest child, rather than continuing throughout the life-course, gradually moving up the urban hierarchy. Using these methods, the intra-generational interpretation of step-migration should no longer be considered a "law". (In addition to the present study see: Plane et al. 2005; Anderson 1971; Mills/Schürer 1996). 
In order to analyse migration using census material, both individuals' birthplace and place of residence on census night must be matched to a GIS (Geographical Information System) and the urban hierarchy must be defined. While the methodology adopted to match individuals' place of birth as transcribed to a GIS will be comprehensively detailed in a forthcoming article, it is worth briefly restating the method here. Firstly, birthplace information in the original manuscript census returns was transcribed as text strings in the form PARISH / TOWN | COUNTY | COUNTRY in line with the original census instructions, with each field being completed with as much - or as little - information as originally recorded. Matching these strings to the GIS was complicated by ambiguities in the birthplace strings; chiefly misspellings, non-existent places, e.g. ABBOTS LANGLEY | STAFFORDSHIRE | [BLANK] or strings that could refer to multiple places, e.g. NEWTON | CAMBRIDGESHIRE | [BLANK]. Despite errors and ambiguities, the core principle of the matching process was to believe that the birthplace individuals provided - however ambiguous - was a meaningful one. Consequently, in order to match with a known location, the original birthplace string was changed as little as possible. For example, if an individual gave simply LONDON | [BLANK] | [BLANK] as their place of birth or NEWTON | CAMBRIDGESHIRE | [BLANK] individuals were matched to all the parishes to which they may have been referring. In these cases, all the parishes that were considered part of London, and all the parishes in Cambridgeshire which included a settlement called "Newton", respectively.

The algorithm matching birthplace strings to a GIS is designed to find the shortest known place name that matches the most characters in each word in the PARISH / TOWN part of the birthplace string, with the fewest redundant characters. For example, S PANCRAS | LONDON | [BLANK] matches to both Pancras, Devon and St Pancras, London on seven characters, "PANCRAS", with one redundant character, "S". As "Pancras" is shorter than "St Pancras", the first parse of the algorithm matches the string to Pancras, Devon. In pre-processing, all strings were matched to a standardised version of the county as stated in the birthplace string. As the "stated" county for the string S PANCRAS | LONDON | [BLANK] was London, a second parse searches for the best match closer to London than Devon, in both London and counties adjacent to it. The condition of matching to the shortest place name is removed in the second parse, so although S PANCRAS matches both Pancras, Devon and St Pancras, London on seven characters with one redundant character, St Pancras, London is closer to the "stated" county than Pancras, Devon. The second parse therefore reallocates the match to St Pancras, London. Similarly, ABBOTS LANGLEY | STAFFORDSHIRE | [BLANK] is matched to Abbots Langley, Hertfordshire rather than Abbots Bromley, Staffordshire. Even though Abbots Bromley is the best match either in or adjacent to the county stated, it matches just six characters with seven redundant characters compared to Abbots Langley, Hertfordshire which matches on thirteen characters with zero redundant characters. The results of this algorithm is compared to the results of one based on Levenshtein Distances, which match a string to a known place name that requires the fewest "edits" to the string to produce a match (Schürer et al. 2015). Where there is a conflict between the places 
which the two methods have matched a string to, precedence is given to the place that is closest to the county as stated in the string.

As already outlined, the core principle underlying the matching process is the assumption that all birthplaces were intended to be meaningful. Therefore, individuals are matched to all the parishes to which they may have been referring. For example, those whose birthplace string was APPLEDORE | [BLANK] | [BLANK] were matched to Appledore in both Kent and Devon. However, if they were resident in Kent they were unlikely to have been born in Devon. Therefore, rather than being matched to all possible birthplaces, individuals were matched to the parish which was the shortest distance from their parish of residence.

In order to identify migration up and down the urban hierarchy, towns and cities were ordered by size and classified into quintiles, grouping together urban settlements which combine to form 20 percent of the urban population of England and Wales outside of London. A GIS of these towns and cities was created from the dataset published by Smith et al. (2018) and spatially matched to individuals' parish of birth. London is categorised separately at the top of the urban hierarchy owing to its size. The number of towns and cities in each quintile and the labels used to describe them is summarised in table 1 and follow those in Plane et al. (2005). Micropolitans represent the smallest urban settlements and are therefore on the lowest rung of the urban hierarchy while London is at the top with "Major Metropolitans" just below it. The colour codes of each metropolitan area correspond to the colours in the appendix and indicates which urban classification each settlement had been allocated and its population in each census year.

Tab. 1: Number of settlements in each urban classification, England and Wales 1851-1911

\begin{tabular}{lrrrrrr}
\hline Urban classification & 1851 & 1861 & 1881 & 1891 & 1901 & 1911 \\
\hline Major Metropolitan & 3 & 3 & 4 & 4 & 4 & 5 \\
AAA Metropolitan & 9 & 10 & 13 & 13 & 14 & 17 \\
AA Metropolitan & 19 & 22 & 33 & 33 & 37 & 43 \\
A Metropolitan & 39 & 46 & 66 & 70 & 86 & 100 \\
Micropolitan & 81 & 90 & 146 & 187 & 224 & 238 \\
Total towns and cities & 150 & 170 & 261 & 306 & 364 & 402 \\
\hline
\end{tabular}

Source: Author's calculations using data from Smith et al. 2018

As the manuscript census returns are cross-sectional, the following sections analyse migration at key life events; leaving home, leaving service and marriage. Each of the following sections shows that the evidence is not consistent with the stepmigration thesis. Firstly, migrants had a similar age profile to those leaving home, suggesting that the two events were part of the same process, with most migratory activity concentrated in early adulthood rather than spread over the lifecycle as migrants moved up the urban hierarchy. Secondly, rural migration to the towns and 
cities is analysed and the extent to which servitude represented a migratory "step" migration is examined. Here, whereas rural-born male farm servants only moved to the towns and cities upon leaving service, rural-born females tended to enter urban domestic service. However, rather than using the town in which they worked as stepping-stones to larger, more distant towns, they largely stayed there upon leaving service. Thirdly, the extent to which the urban-born population moved up the urban hierarchy is considered. Here the evidence suggests that migrants moving up the urban hierarchy were outweighed by the number moving down, resulting in no net upward migration amongst the urban-born. The last section conducts a pseudolongitudinal analysis by tracking mothers' migration paths through the birthplaces of her co-resident children. This shows that the moves which occurred prior to the birth of the eldest co-resident child were the most significant. When combined with the rest of the evidence presented in this article, individuals' migration paths were clearly not stepwise, but rather, were concentrated in their first, major move.

\section{$3 \quad$ Age profile of migrants}

Although the theory of step-migration has garnered widespread acceptance, it makes little sense in light of what else is known about the demographic history of late nineteenth- and early twentieth-century England and Wales. Firstly, as Ravenstein (1876) first observed and others have replicated, the young and single were the most migratory. When this is put into the context of the age at leaving home, leaving service and then marriage, it represents a very small timeframe for stepmigration and the several moves towards ever-larger towns and cities to occur. Table 2 shows the ages of leaving home, leaving service and marriage for males and females across England and Wales between 1851 and 1911 (Day 2018. See also: Hajnal 1953; Schürer 1989, 2003).

This table shows that the gap between leaving home and marriage shrank from around 7.5 years to 6.5 years in the period between 1851 and 1911, despite a rising

Tab. 2: $\quad$ Mean ages of key lifecycle transitions, England and Wales, 1851-1911

\begin{tabular}{lcrrrrr}
\hline Year & \multicolumn{2}{c}{ Age at Leaving Home } & \multicolumn{2}{c}{ Age at Leaving Service } & \multicolumn{2}{c}{ Age at Marriage } \\
& Male & Female & Male & Female & Male & Female \\
\hline 1851 & 19.2 & 17.8 & 22.5 & 22.9 & 26.7 & 25.7 \\
1861 & 19.2 & 17.7 & 21.9 & 22.5 & 26.2 & 25.3 \\
1871 & $\mathrm{n} / \mathrm{a}$ & $\mathrm{n} / \mathrm{a}$ & $\mathrm{n} / \mathrm{a}$ & $\mathrm{n} / \mathrm{a}$ & $\mathrm{n} / \mathrm{a}$ & $\mathrm{n} / \mathrm{a}$ \\
1881 & 20.1 & 18.0 & 22.2 & 22.6 & 26.4 & 25.2 \\
1891 & 20.5 & 18.6 & 22.7 & 23.1 & 26.9 & 25.8 \\
1901 & 21.1 & 19.3 & 23.1 & 23.5 & 27.2 & 26.2 \\
1911 & 21.6 & 19.7 & 23.8 & 23.7 & 27.6 & 26.3 \\
\hline
\end{tabular}

Source: Author's analysis based on data from UK Data Service SN 7481 (Schürer 2019) 
age at marriage as the age at leaving home increased by approximately two years for females and two and a half years for males, squeezing the mean number of years spent in service by around a year in both the male and female case. Therefore, if - as has already been demonstrated in countless studies - young, unmarried men and women were by far the most migratory, the window of time they had to migrate up the urban hierarchy between leaving home and marriage was relatively limited (Bowley 1914; Hill 1925; Hollingsworth 1970; Llewellyn-Smith 1902; Ravenstein 1876). In order to demonstrate that migration was indeed compressed into a relatively narrow age window - largely between the ages of 15 and 24 - this article extends the method proposed by Hinde (2004) and shows that migratory activity peaked in the 15-24 year-old age group throughout the period between 1851 and 1911 in England and Wales.

Following the logic that Net Migration $=\left(\right.$ Population $_{(t+1)}-$ Population $\left._{t}\right)$ - Births - Deaths), mortality rates ${ }_{n} M_{x}$ and survival probabilities ${ }_{n} P_{x}$ are calculated in order to estimate intercensal age-specific net migration rates (Newe/l 1988; Hinde 1998). Intercensal net migration figures were not calculated for the periods $1861-1871$ or $1871-1881$ as the 1871 mortality figures in the Registrar-General's Decennial Supplements did not distinguish between male and female deaths. The age- and sex-specific mortality rates across approximately 600 registrations districts (RDs) between 1851 and 1911 were then used to estimate the population that survived the intervening decade in each of the approximately 2,000 registration sub-districts (RSDs) into which the RDs were sub-divided. Each parish is a further sub-division of each RSD. Details of the spatial units in which official statistics were collected and their relationship to one another are fully described in Satchell (2011). This approach narrows the window in which migration must have occurred to a ten-year period. In order to analyse the age groups in which migratory activity was concentrated, it would be useful to calculate the population turnover. This however requires being able to calculate the number of both in-migrants and out-migrants in each age group in each decade which is not possible from either the published census reports or the manuscript census returns. Therefore, the usual formula for population turnover could not be used (Dennett/Stil/we/l 2008), and a "pseudo" measure of population turnover is used instead. In the formula below, $D_{i}^{\alpha s}, O_{i}^{\alpha s}$ and $P_{i}^{\alpha s}$ respectively, represent in-migration, out-migration and population of those in age group $\alpha$ and sex group $s$ in area $i$. In this case, each area $i$ represents each RSD.

$$
T O_{i}^{a s}=\left(\frac{D_{i}^{a s}+O_{i}^{a s}}{P_{i}^{a s}}\right)
$$

However, as the absolute number of in- and out-migrants in each age group is unknown, the number of net in- and out-migrants must substitute. Therefore, for each age group, RSDs were classified according to whether there were net inmigrants or net out-migrants. For each age group in each intercensal period, the total net in- and out-migrants across the RSDs substitute for the absolute number of in- and out-migrants $-D_{i}^{\alpha s}$ and $O_{i}^{\alpha s}$ respectively - and are divided by the total population of that age group $-P_{i}^{\alpha s}-$ in much the same way as the formula above. 
Between 1881 and 1890, 327 of the 2,110 RSDs made a net gain of 175,807 males aged 20-29 while 1,783 RSDs made a net loss of 450,755 males in the same age bracket of a total population of 2,318,531. The discrepancy between the two figures is largely explained by net emigration (Baines 1986). Therefore; $\frac{(175,807+450,755)}{2,318,531}=0.27$ or more precisely, 270.2 per thousand. However, as figure 3 underestimates actual population turnover, they must be interpreted as being indicative only of migrants' age structure for two reasons. Firstly, as in- and out-migration is calculated from net migration figures, the absolute number of both in- and out-migrants is likely to be higher. Secondly, as only those that moved between RSDs are counted as migrants, those that migrated within an RSD are not included in these figures.

Despite these shortcomings, and despite clear differences in the volume of migratory activity between males and females and significant changes over time, figure 3 demonstrates that there was an extremely clear age profile to migratory activity. Although male migration appears to have been concentrated in a far shorter age range compared to the female experience - whose migratory activity was a little more spread out over the age range - for both males and females, the 15-24 age group emerges as the age group in which most migration occurs. When this is compared to the age profile at which the population either leaving the parental home or leaving service, it appears to exhibit an extremely similar age profile which suggests that the process of leaving home and migrating were part of one-and-thesame process.

Figure 4 shows the year-on-year increase in the age-specific proportion of the population that were either no longer in the parental home or no longer in service. In 1881 for example, 48 percent of 21 year-old males had exited home or service compared to 56 percent of 22 year-olds. This is graphed as an 8 percent increase in the proportion leaving home at the age of 22. Like figure 3, there are some noteworthy differences between the male and female experience. The female process of leaving home exhibits a rapid "take-off" from the age of 15 whereas the male process did not. However, what is clear is that the central 50 percent of the population - in all census years - were leaving home or service and becoming independent between the approximate ages of 20 and 29; the same age group in which migratory activity was concentrated. Therefore, although figure 3 shows that migratory activity did not solely occur in the 20-29 year age group, figure 4 shows that nor did the leaving home process. Rather, both sets of graphs illustrate that the age profile of the leaving home process was largely coincident with the age profile of migration. Whereas figure 3 might previously have been interpreted as evidence that migration continued throughout the lifecycle - in support of the step-migration hypothesis - when it is combined with figure 4 , it is perhaps more convincing to argue that moves later in the lifecycle are evidence of delayed first moves from the parental home rather than multiple moves. This contradicts Llewellyn-Smith (1902), who interpreted a higher average age among migrants to London as being consistent with step-migration theory given that migrants would be older at the point of their final migratory step to the city compared to their first migratory step out of the countryside. While this is consistent with what would be expected if migration were indeed stepwise, in light of the evidence presented here, a more convincing interpretation might he that 
Fig. 3: Age-specific pseudo population turnover, England and Wales 1851-1911

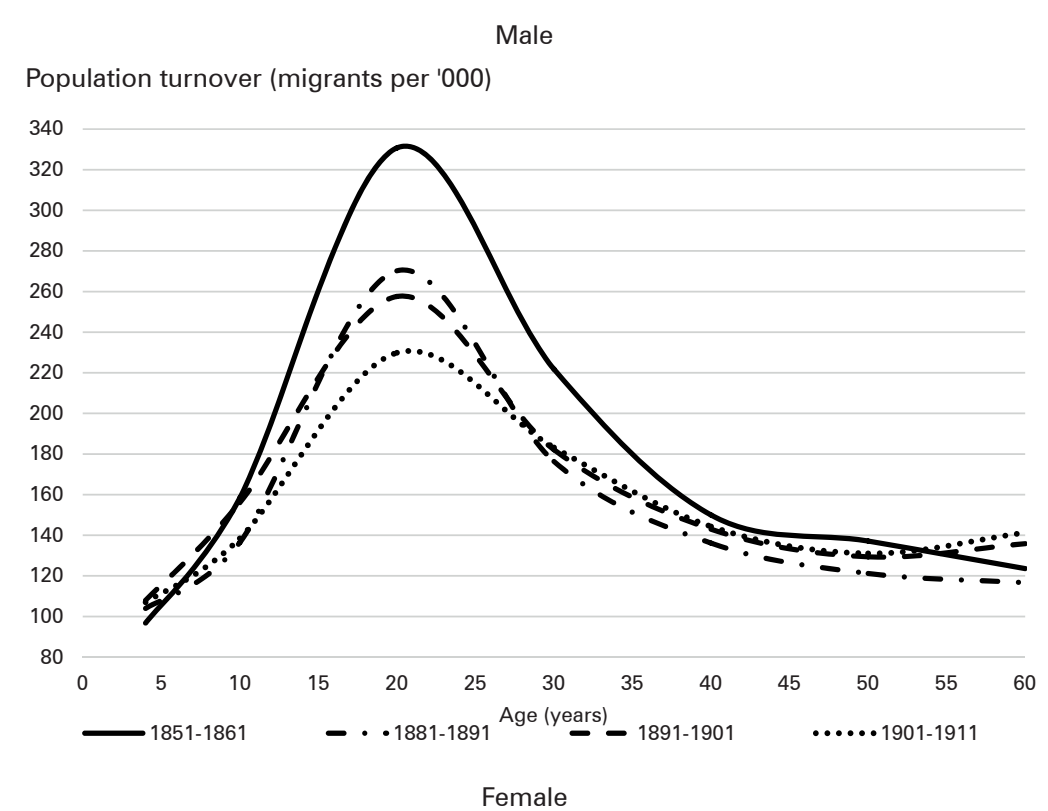

Population turnover (migrants per '000)

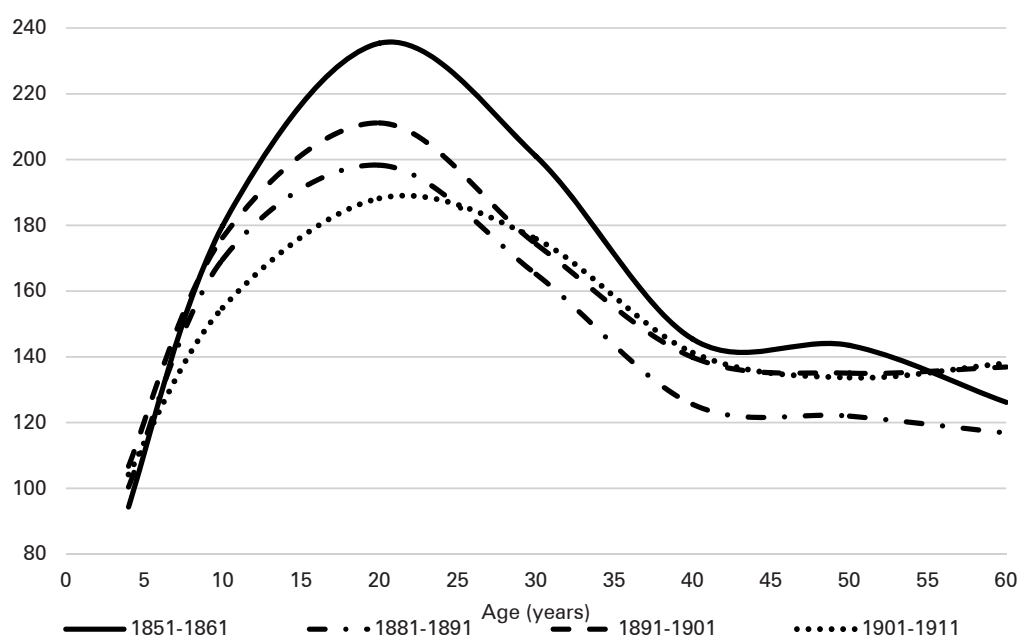

Source: Author's analysis based on data from UK Data Service SN 7481 (Schürer 2019)

migrants to London were simply delaying a first move and giving themselves more time to save and accumulate the resources necessary for such a move (Williams/ Baláž 2012).

This section has argued that if the step-migration hypothesis were true, these multiple steps would need to be completed within a relatively small window, contra- 
Fig. 4: Year-on-year increase in \% leaving home or service England and Wales, 1851-1911

Male

$\%$ year-on-year increase

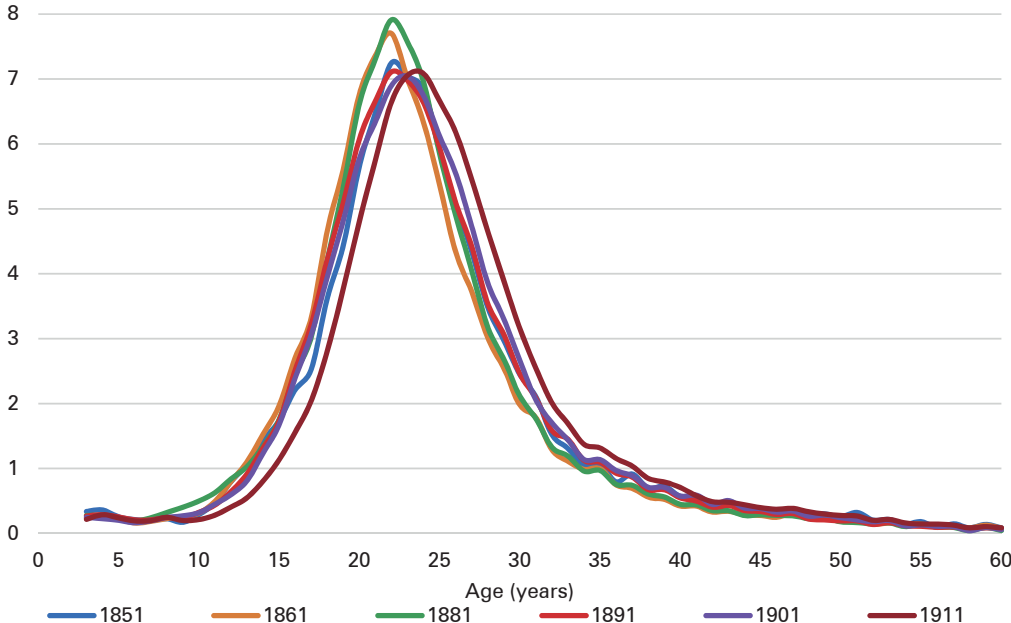

Female

$\%$ year-on-year increase

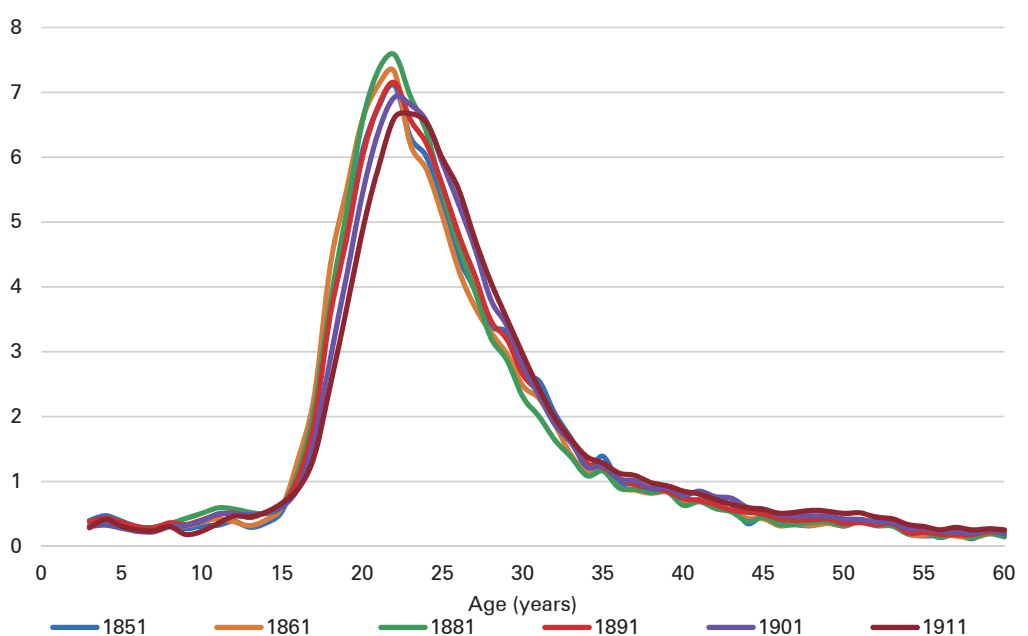

Source: Author's analysis based on data from UK Data Service SN 7481 (Schürer 2019)

dicting not only the evidence presented here and elsewhere, but also Ravenstein's "law" of migration that the young and unmarried that were the most migratory (Ravenstein 1876). Instead, leaving the parental home appears to have been the principal mechanism by which migration occurred, and that moves later in life are more likely to have been the product of leaving home later, rather than multiple stepwise 
moves. In order to clarify this process further, the remaining sections examine the extent to which other key life events; lifecycle service and marriage, represented "steps" in the step-migration hypothesis and whether any moves that were taken subsequent to leaving home were indeed stepwise moves up the urban hierarchy. The next section considers whether entering lifecycle service represented a first migratory "step" up the urban hierarchy for male and female migrants or can instead be better described as "circulating" migration (Kussmaul 1981).

\section{$4 \quad$ Leaving home and entering service: a first "step"?}

Before analysing age-specific migration paths, it is useful to acknowledge that in large parts of England and Wales, lifecycle service was an important institution; men predominantly entering farm service while women mainly went into domestic service. Therefore, did entering service represent the first "step" in migrants' journeys up the urban hierarchy? Firstly, it is necessary to identify the population for whom service represented the "modal" experience upon leaving the parental home. Figures 5 and 6 show the proportion of males in 1851 and 1911 that had entered service upon leaving home. This is estimated by first calculating the male and female mean age at leaving home in each RSD in each census year (Day 2018). Those that were aged within two years of the mean age at leaving home and were not resident with parents approximate the population that had likely left home shortly before census night. The proportion of this group that were servants therefore serves as an estimate of the likelihood of entering service upon leaving home.

Although it is evident in the male case that the institution of service was in terminal decline throughout the second half of the nineteenth century and had all but disappeared from the south-east by 1911, farm service still played an important - if diminished - role in the rural labour market across Wales, the South West of England, Lincolnshire, the North and East Yorkshire Ridings and Cumberland in 1911. In the female case in figures 7 and 8, service still predominated across England and Wales throughout the period. Despite straw-plaiting and lace-making in the Home Counties providing women with an alternative to domestic service until the industry was killed off by foreign competition, while textile employment in the north-west similarly gave women an alternative to lifecycle service, domestic service remained the principal route out of the parental home in nineteenth-century England and Wales (You 2020).

If leaving home was the first step of many, one would expect evidence of additional moves. However, as the dataset used here is not record-linked and it is not possible to reconstruct individuals' migration paths directly, figure 9 shows the average distances migrated by the time individuals had left home, left service or had married. Like figures $5-8$, this has been estimated by calculating the mean age at leaving home, leaving service and entering marriage - as in table 2 - for each RSD in each census year. Only those that were aged within two years of the average age of leaving home/service/marriage and were not at home or in service were included in the measure. This was so it could be plausibly inferred they had only left home/ 
Fig. 5: Estimated \% of males entering service upon leaving home, England and Wales 1851

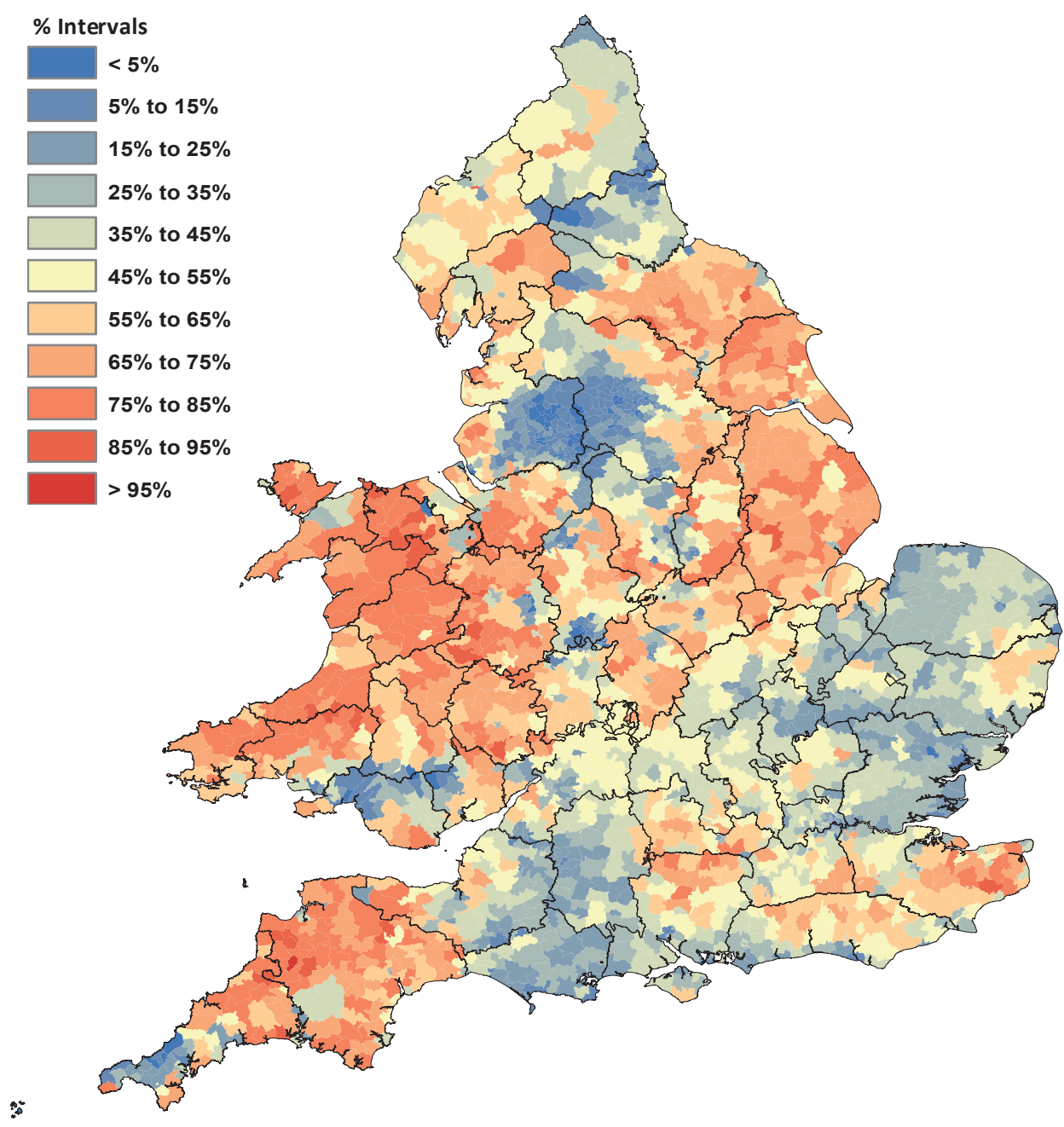

Source: Author's analysis based on data from UK Data Service SN 7481 (Schürer 2019)

left service/entered marriage recently prior to the census being taken and so were unlikely to have made any intermediate steps between birth and census night. Figure 9 distinguishes between the distances travelled upon leaving home by those that entered service and those that did not.

The "farm service" and "non-service" districts in figure 9 are defined as those RSDs in which more/less than half of males became servants upon leaving home using the same methodology as figures $5-8$, as males that entered service were overwhelmingly farm servants and the manuscript census returns rarely identify agricultural servants specifically. The differences are striking. Males that left home 
Fig. 6: Estimated \% of males entering service upon leaving home, England and Wales 1911

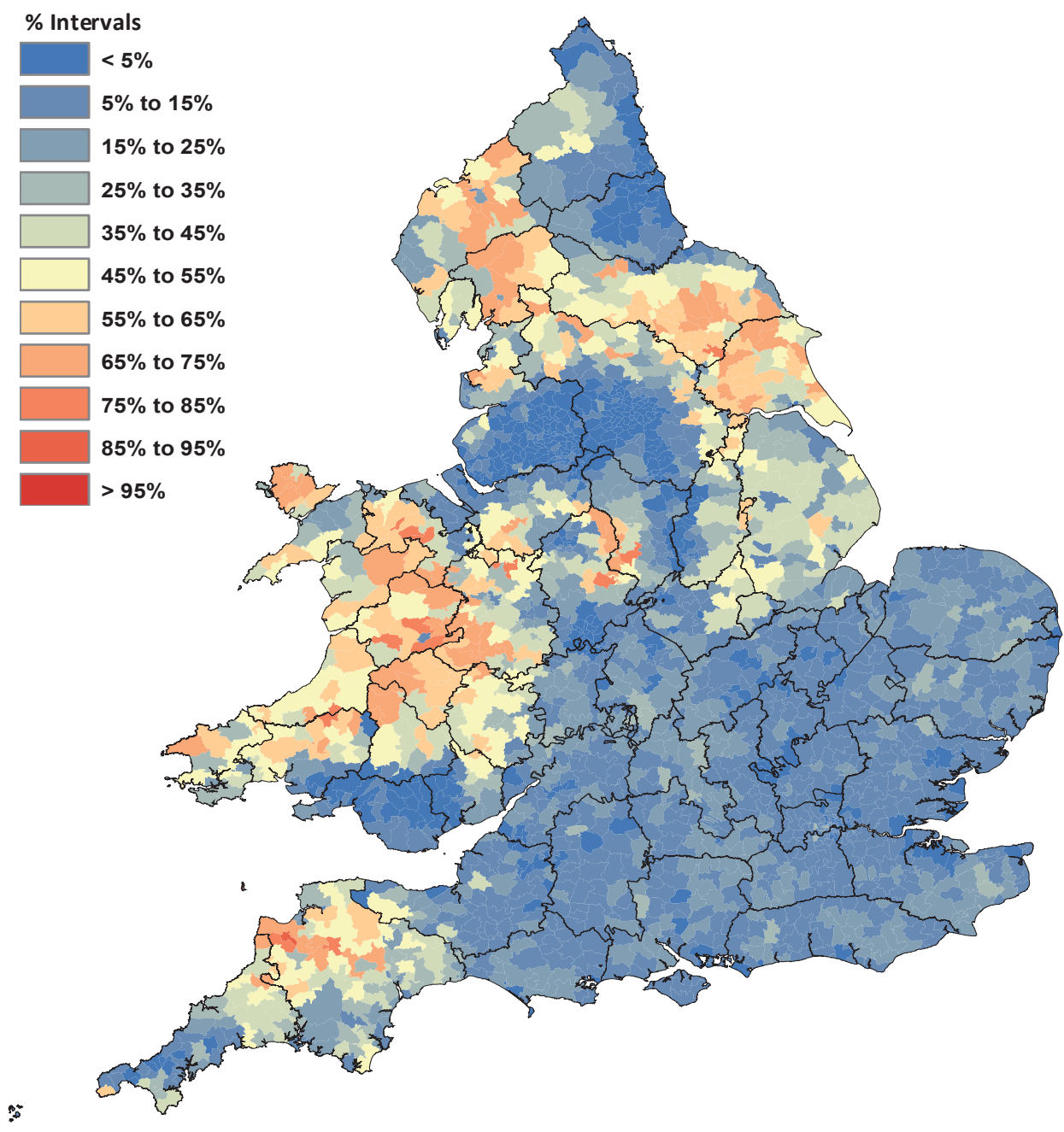

Source: Author's analysis based on data from UK Data Service SN 7481 (Schürer 2019)

to enter farm service were far and away the least migratory group, moving on average around $15 \mathrm{~km}$ from the parental home to enter service which is in stark contrast to the distance migrated by those that did not enter service. Those that left home and did not enter service had migrated - on average - around the same distances as by the age at marriage, implying that the majority of those not entering service did not migrate beyond the move made at leaving home. Once individuals left service however, the distances migrated increased dramatically.

Although the population at the age of leaving service also includes those that had never been in service; as this is not a record-linked dataset it is not possible to 
Fig. 7: Estimated \% of females entering service upon leaving home, England and Wales 1851

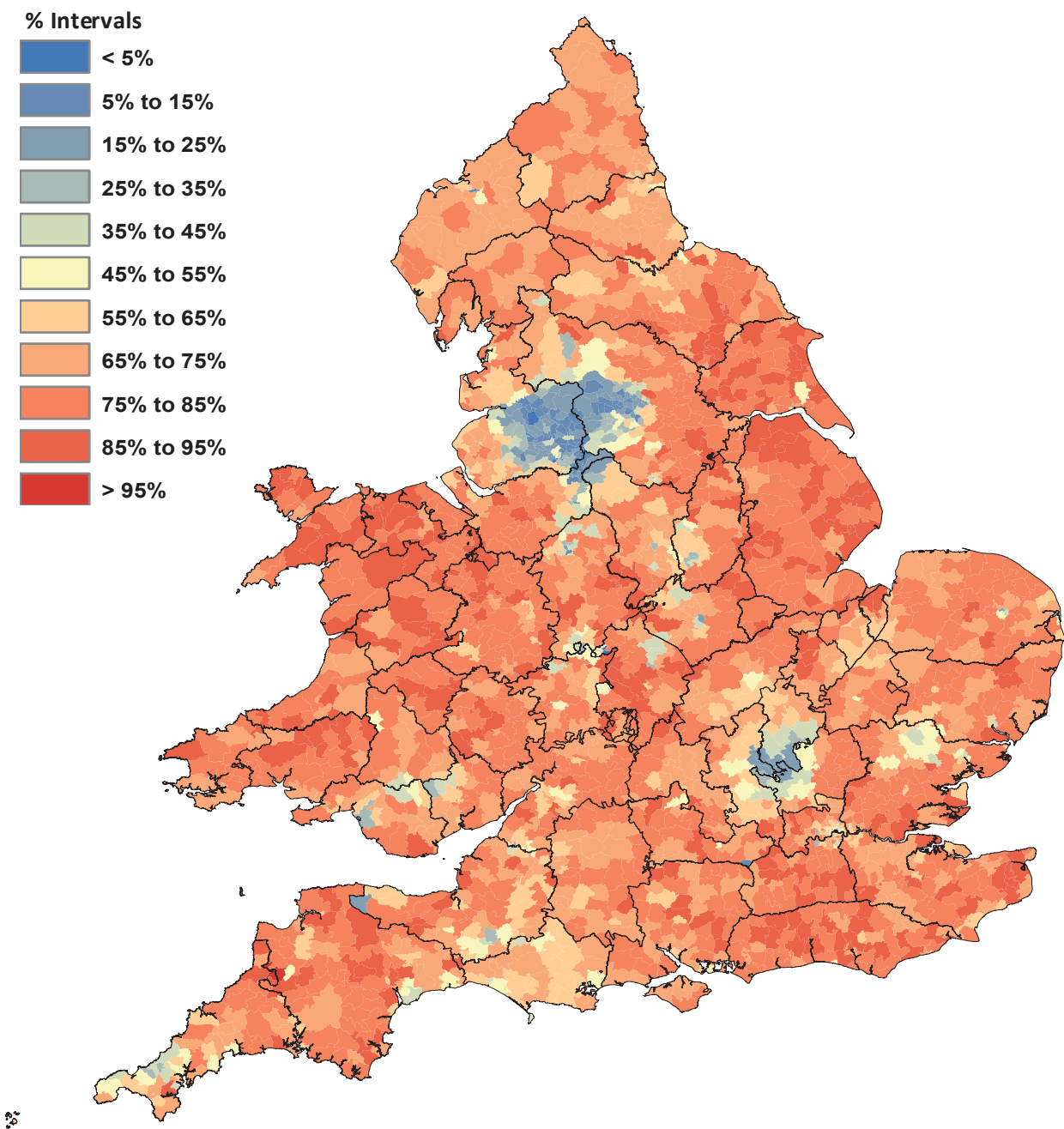

Source: Author's analysis based on data from UK Data Service SN 7481 (Schürer 2019)

determine whether individuals had ever been servants prior to census night, the implication is clear. Farm service simply delayed the moment in the lifecycle at which migration occurred rather than deterring it completely. Like those that had not entered service however, former farm servants tended not to migrate any further between leaving service and entering marriage, indeed the average distance migrated from individuals' birthplaces actually went down slightly between leaving service and marriage. This suggests that migrants were not moving in steps - making a series of small migratory steps towards ever-larger settlements at each lifecycle stage - but instead that they were making a single move at the point of either leaving 
Fig. 8: Estimated \% of females entering service upon leaving home, England and Wales 1911

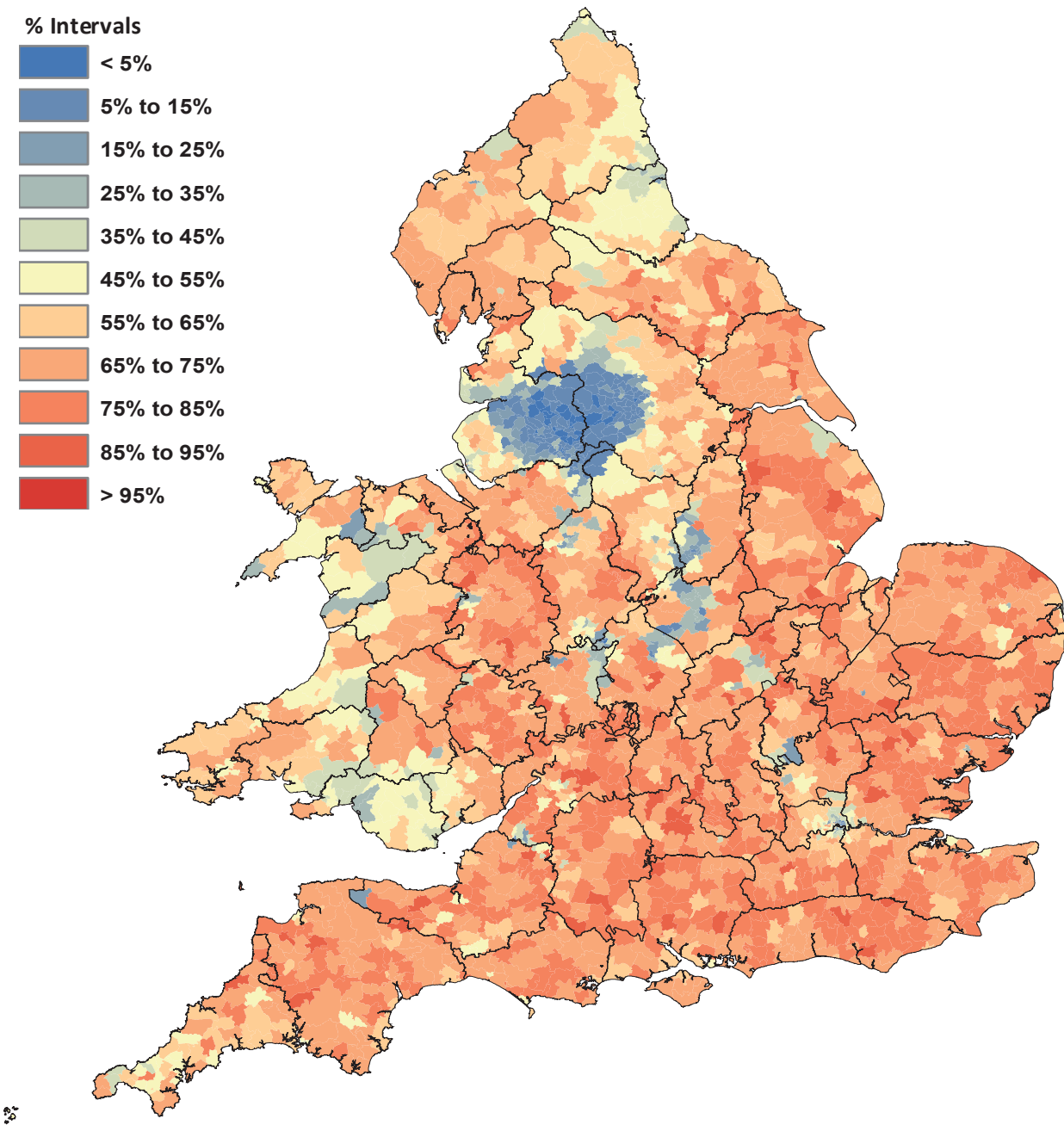

Source: Author's analysis based on data from UK Data Service SN 7481 (Schürer 2019)

home or leaving service. However, figure 9 also shows that there was at least some movement between leaving home and marriage in the female case. For most males on the other hand, the average distance migrated hardly increased between leaving home and marriage; any difference between the two largely being accounted for by farm service. So, was this extra distance migrated by females between leaving home and marriage evidence of step-migration - a substantial proportion of the population moving a relatively short distance up the urban hierarchy - or evidence of a small number becoming more migratory between lifecycle events? Figure 10, however, shows that it was likely to be the latter. It shows that there was a significant 
Fig. 9: $\quad$ Mean distance $(\mathrm{km})$ migrated by the rural-born population at each lifecycle stage, England and Wales 1851-1911

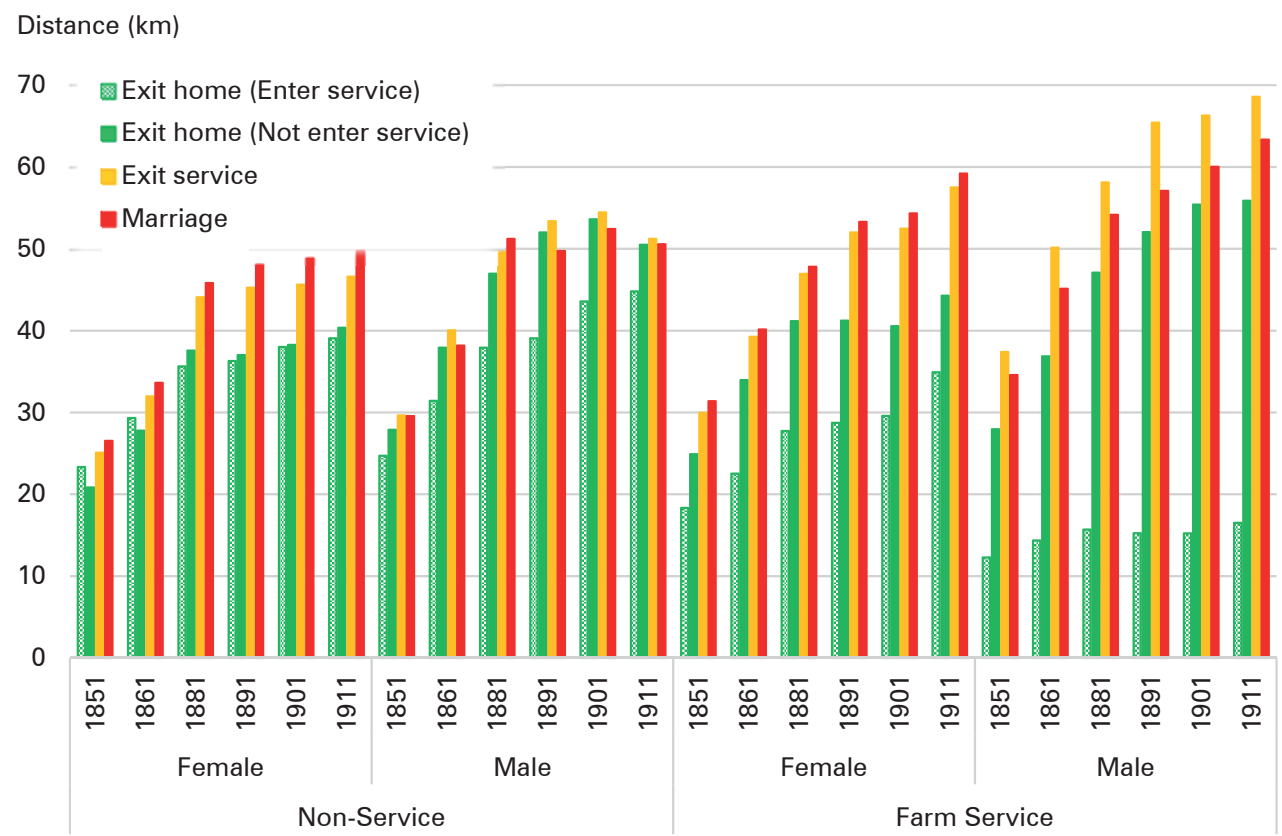

Source: Author's analysis based on data from UK Data Service SN 7481 (Schürer 2019)

decline in the proportion of "non-movers" - those that migrated less than $1 \mathrm{~km}-$ between the ages of leaving home and marriage. This suggests that there was not necessarily stepwise migration - which would more likely have expressed itself as drop in the $<1 \mathrm{~km}$ bracket and a proportional increase in the $\geq 100 \mathrm{~km}$ bracket as migrants moving out of one distance interval were replaced by those moving into it in a "wave-like" motion (Redford 1926). Instead, a significant proportion of those that had not moved upon leaving home, suddenly did so upon marriage. Consequently, rather than being evidence of step-migration - moving upon leaving home and then again upon marriage as is implied by figure 9, figure 10 shows that, although the majority moved upon leaving either home or farm service, a minority made no significant move at either of these milestones, instead delaying any migration until they were married. Therefore, rather than being evidence of multiple "stepwise" moves, closer scrutiny suggests the first move was simply delayed.

Whereas figure 10 suggests that figure 9 was evidence of a small proportion migrating between leaving home and marriage rather than evidence of a more widespread secondary move, figure 11 demonstrates that whatever the mechanism, it did not translate into migration up the urban hierarchy. Rather, the type of settlement they were in when they left home was the same type of settlement they were likely to be in upon getting married. Although figure 11 could be masking a significant volume of movement up and down the urban hierarchy between lifecycle events, the 
Fig. 10: Distances migrated by rural-born females leaving home (not into service) vs. marriage, England and Wales 1851-1911

$\%$ of migrants

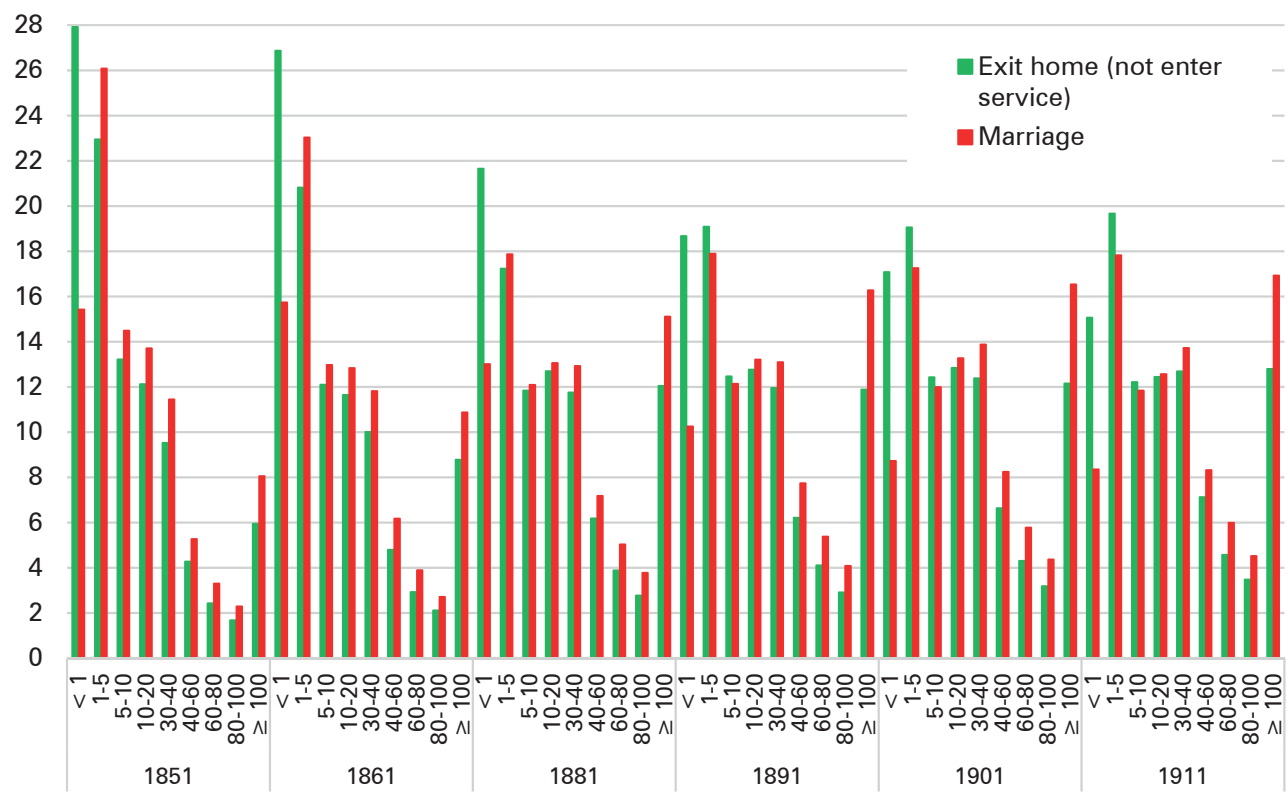

Source: Author's analysis based on data from UK Data Service SN 7481 (Schürer 2019)

point remains that there is no evidence of step-migration in the aggregate. Indeed, if migrants had moved in a stepwise fashion, one would have expected an ever-larger proportion to be located in ever larger settlements at each successive lifecycle stage. This was evidently not the case; with the exception of males that move to the towns upon leaving service rather than leaving home.

Clearly then, a cross-sectional analysis of the data suggests that migrants tended to make a single move between leaving home and marriage. While males that entered farm service delayed their move to the towns and cities, those that did not made their primary move upon leaving home, and did not migrate again. Similarly, a large proportion of females that did not enter service upon leaving home appear to have delayed migrating until marriage - figure 10 indicates that 20-30 percent between 1851 and 1911 had migrated less than $1 \mathrm{~km}$ from their birthplace upon leaving home, but dropped to half this by the time they married. While the evidence presented shows no evidence of step-migration, a cross-sectional study assumes that different cohorts had comparable experiences. It is useful therefore to try and follow the destinations of each cohort through the censuses in figure 12. Figure 12 removes the effect of urbanisation inflating the number of rural-urban migrants over time, towns and cities are defined by their boundaries as they existed in 1911 throughout the period 1851-1911. Figure 12 therefore includes only those that were neither in service nor co-resident with their parents and who were aged within two years of the mean age at leaving service for their RSD of birth. For example, if the 
Fig. 11: Destinations of the rural-born at each lifecycle stage, England and Wales, 1851-1911

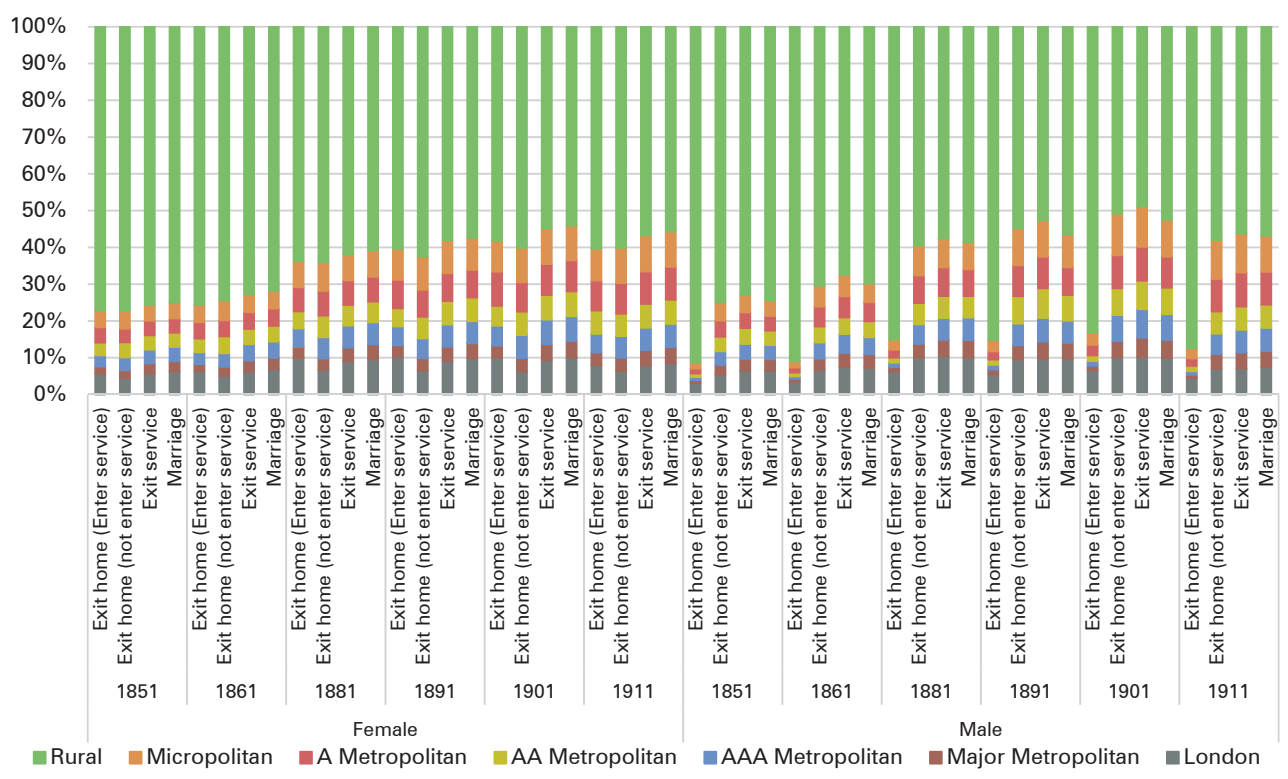

Source: Author's analysis based on data from UK Data Service SN 7481 (Schürer 2019)

mean age of males leaving service in 1851 was 23 , those that were neither at home nor in service between the ages of 21 and 25 in 1851 are included and form the same cohort as those aged 31 to 35 in 1861 that were similarly neither at home nor in service.

Broadly, the picture in figure 12 is one of notable similarity with that shown in figure 11. Overall, there was very little change between the proportions of each cohort found in each settlement type between censuses which suggests a remarkable level of stability, confirming the impression made in figures 9-11 that individuals tended to migrate only once in their lifetime. However, although a relatively minor increase; the proportion of the 1851 and 1861 female cohort migrating to a town or city increases from 30.0 percent to 41.7 percent between 1851 and 1911 and from 33.7 percent to 44.9 percent between 1861 and 1911 respectively. While most other changes in the period can be reasonably attributed to random fluctuations, these increases necessitate a little explication.

Firstly, it is worth noting that no one type of urban settlement appears to have grown at the expense of another, but rather towns and cities from across the urban hierarchy attracted an ever-larger proportion of migrants from the countryside. If individuals' migration paths were stepwise, one would expect larger towns to grow disproportionately faster than towns lower down the urban hierarchy. However, even if this pattern were a function of step-migration - migrants from the countryside relocating to a micropolitan and then those they displaced migrating further up the urban hierarchy and so on - an increase from 30 percent to 40 percent of the 
Fig. 12: Destinations of the rural-born population by cohorts upon leaving service in each census year, England and Wales 1851-1911 (Extent of towns/cities held constant throughout period at 1911 boundaries)

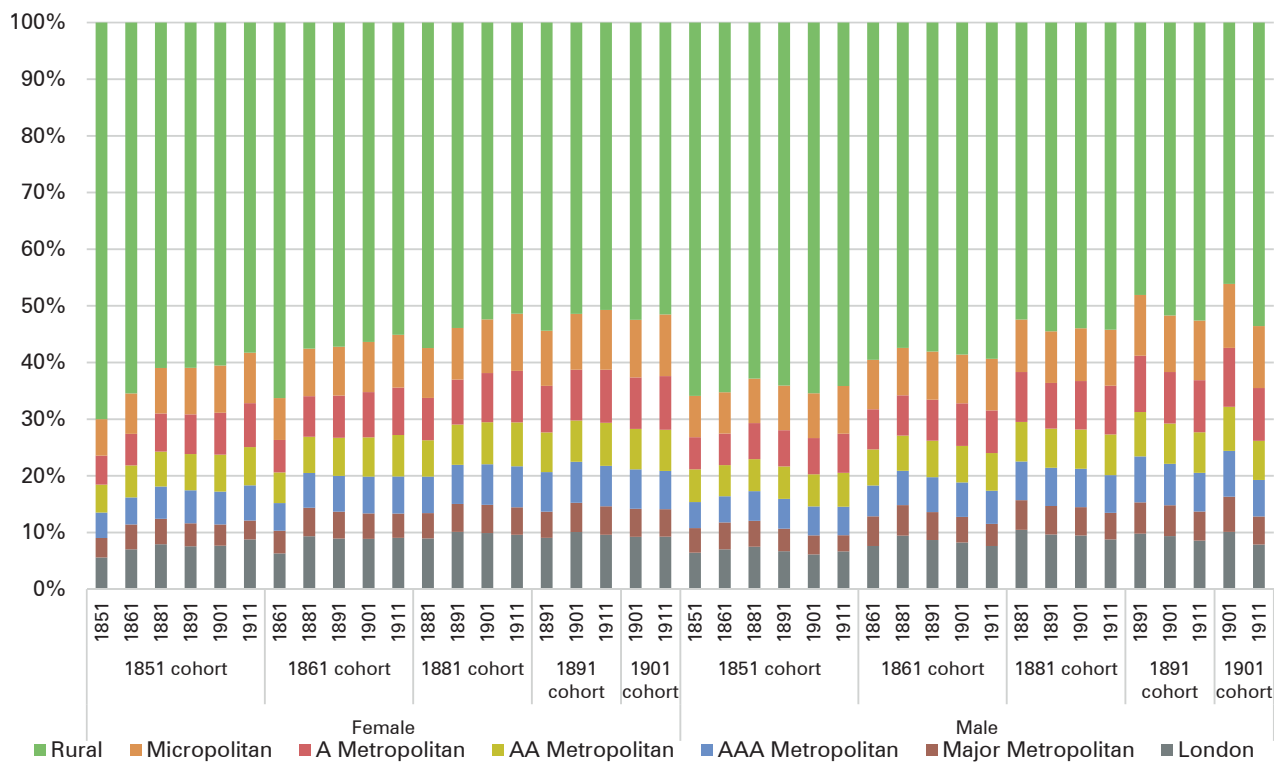

Source: Author's analysis based on data from UK Data Service SN 7481 (Schürer 2019)

rural-born population migrating to towns represents only a quarter of all rural-urban migrants. The remaining three-quarters likely having not migrated beyond the moment they left home.

Secondly, around half of each cohort were still resident with their parents when aged at the "mean" age of leaving home. Fast-forward ten years to the next census and around 85 percent had left home. Although unavoidable in the absence of record-linked data, this age group now includes many that were not included in the first cohort. If the two groups of "early" and "late" leavers had differing propensities to migrate to towns and cities, one would expect it would present itself in the manner shown in figure 12. However, as this dataset is not record-linked, it is not possible to identify the early and late leavers and their characteristics individually; otherwise the theory that rural-born females were more likely to migrate to towns and cities the later they left the parental home, could be tested. For the moment then, it does seem a plausible deduction, especially as it accords with the evidence presented in figures 3-4 which shows a remarkable congruence between the age profiles of migration with those of leaving home. This suggested that migration in later life was not necessarily evidence of step-migration, but perhaps a delayed exit from home instead.

This section has argued that rural migrants - except males entering farm service - tended to go to towns and cities upon leaving home and that most migrants remained in the same town or city that they first migrated to (Gritt 2000). In addition, 
no group appears to have migrated up the urban hierarchy beyond their first move. So, if rural-born migrants did not tend to migrate in steps, were the urban-born population more likely to continue moving "up" the urban hierarchy throughout their lifetime?

\section{$5 \quad$ Urban-born migrants}

The methodology used to identify the cohort in figure 12 is repeated in figure 13 , which shows the proportion of the urban-born population that had either stayed in their hometown, moved to a town or city in the same urban classification or had moved "up" or "down" the urban hierarchy. London-born migrants are excluded as they were at the top of the urban hierarchy and could therefore not move either "up" or "across". It is striking that the pattern in in figure 13 mirrors that of figure 12. Like the increase in the proportion of the 1851 and 1861 cohorts of migrating to towns and cities shown in figure 12 - a probable consequence of differing propensities between early and late leavers to migrate to towns and cities - the 1851 and 1861 urban-born cohorts similarly became marginally more likely to have moved up the urban hierarchy by 1881; from around 11 percent to 17 percent of the total.

However, this should not distract from the principal observation that the modal experience was to stay in the same settlement in which one was born. It is also of note that each cohort became increasingly likely to move down the urban hierarchy over time. From 1851-1911 the urban-born population moving down the urban hierarchy increased from 22 percent to 32 percent of the total. Although a relatively modest increase, it means that in the aggregate, the number migrating down the urban hierarchy always exceeded those migrating up. In terms of stepwise migration then, it appears that it was neither spatial - transferring individuals between settlements - nor hierarchically pushing the population up the urban hierarchy.

Given that figure 13 shows very little migration between census years in each cohort, the move migrants made upon leaving home must have been the most significant move which individuals made in their lifetime. Figure 14 clarifies this and shows very little change in the proportion of the population that had migrated up or down the urban hierarchy between the mean ages of the key lifecycle events; leaving home, leaving service and entering marriage, implying that the overwhelming majority of the moves that did occur, occurred upon leaving home. Like figure 13 , figure 14 shows remarkable stability in the proportions of the population found in each settlement type across the three lifecycle stages, suggesting that for the majority, leaving the parental home was their sole migratory move. However, the observations made in both figures 13 and 14 which require greater exposition is the number of moves down the urban hierarchy, consistently outnumbering those moving up. Of these downward moves, around 60 percent of them were to rural parishes and the distances travelled by these migrants tended to be shorter than the distances travelled by the upwardly mobile as is shown in figure 15 .

Although the differences between distances travelled by upward and downwardly mobile migrants narrowed between 1851 and 1911 as urbanisation shrank 
Fig. 13: Proportion of the urban-born population migrating across the urban hierarchy by cohorts upon leaving service in each census year, England and Wales 1851-1911 (Extent of towns/cities held constant throughout period at 1911 boundaries)

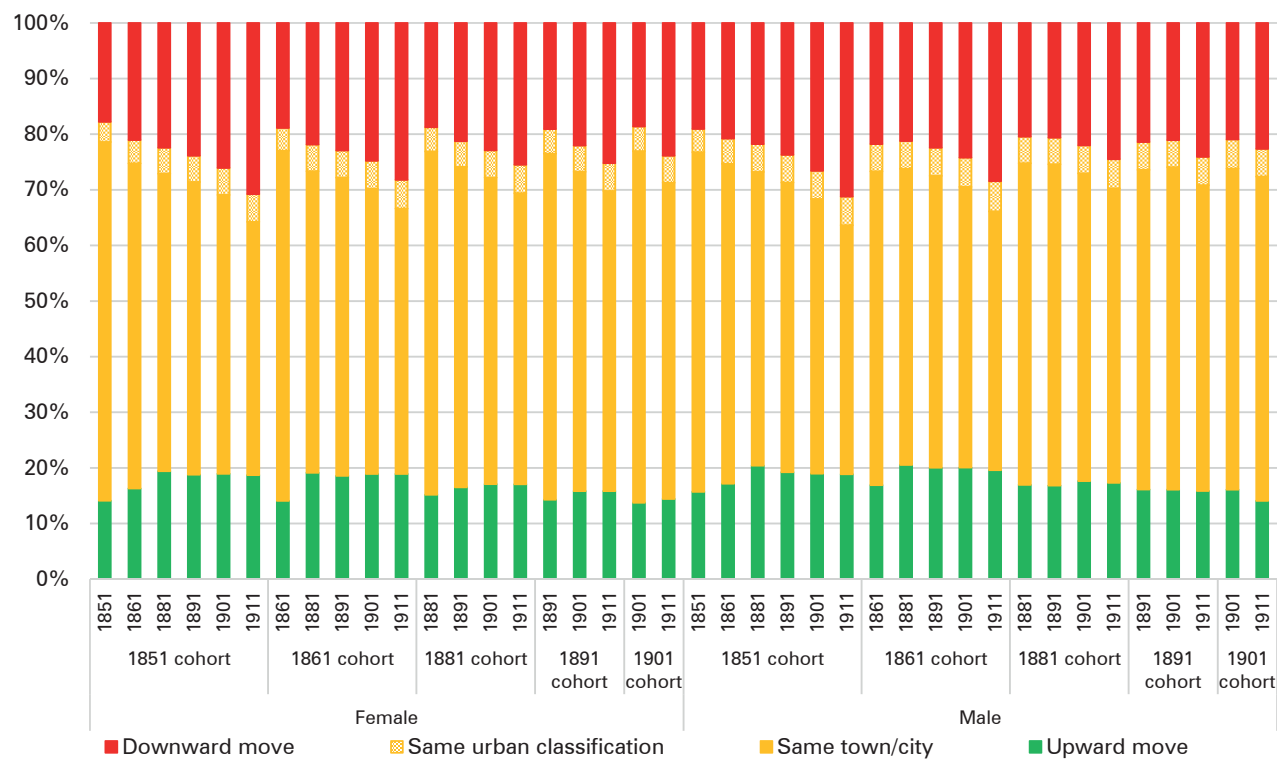

Source: Author's analysis based on data from UK Data Service SN 7481 (Schürer 2019)

Fig. 14: Proportion of the urban-born population migrating across the urban hierarchy by lifecycle stage, England and Wales 1851-1911

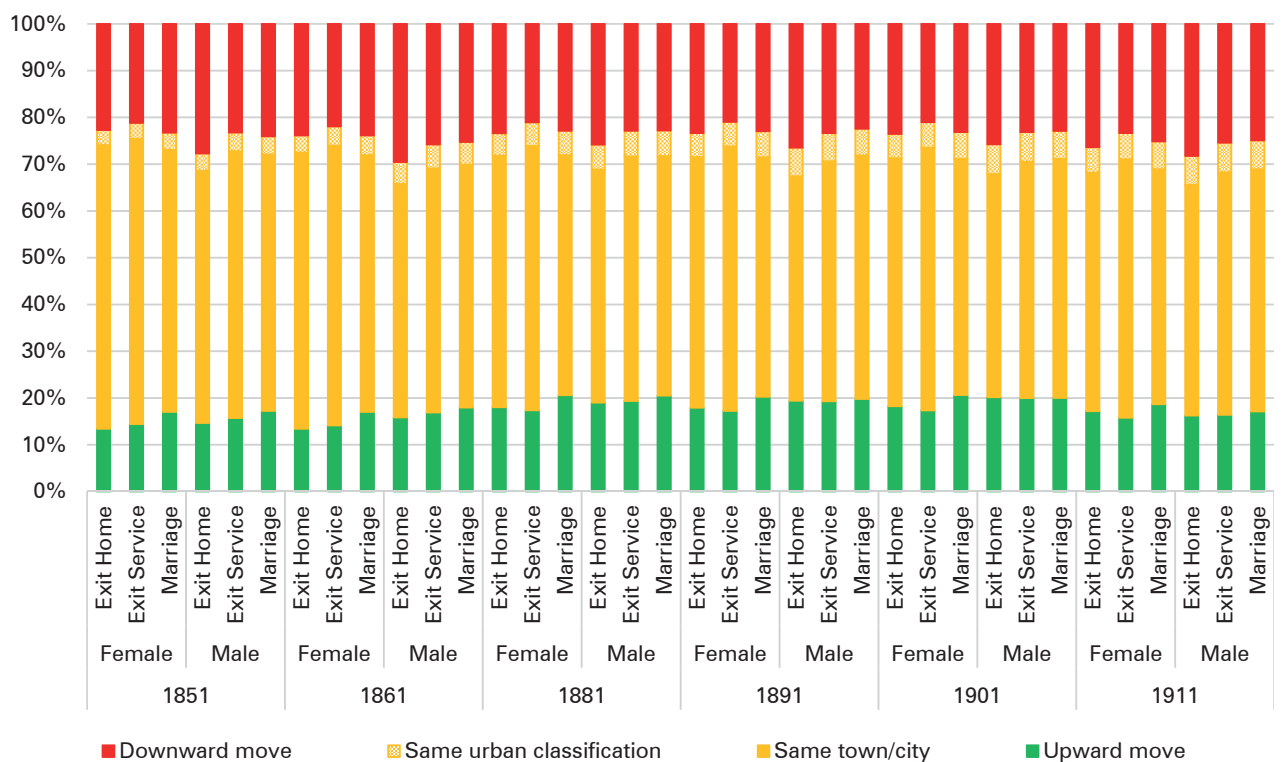

Source: Author's analysis based on data from UK Data Service SN 7481 (Schürer 2019) 
Fig. 15: Cumulative distance $(\mathrm{km})$ migrated by urban-born migrants moving up/ down the urban hierarchy, England and Wales 1851-1911

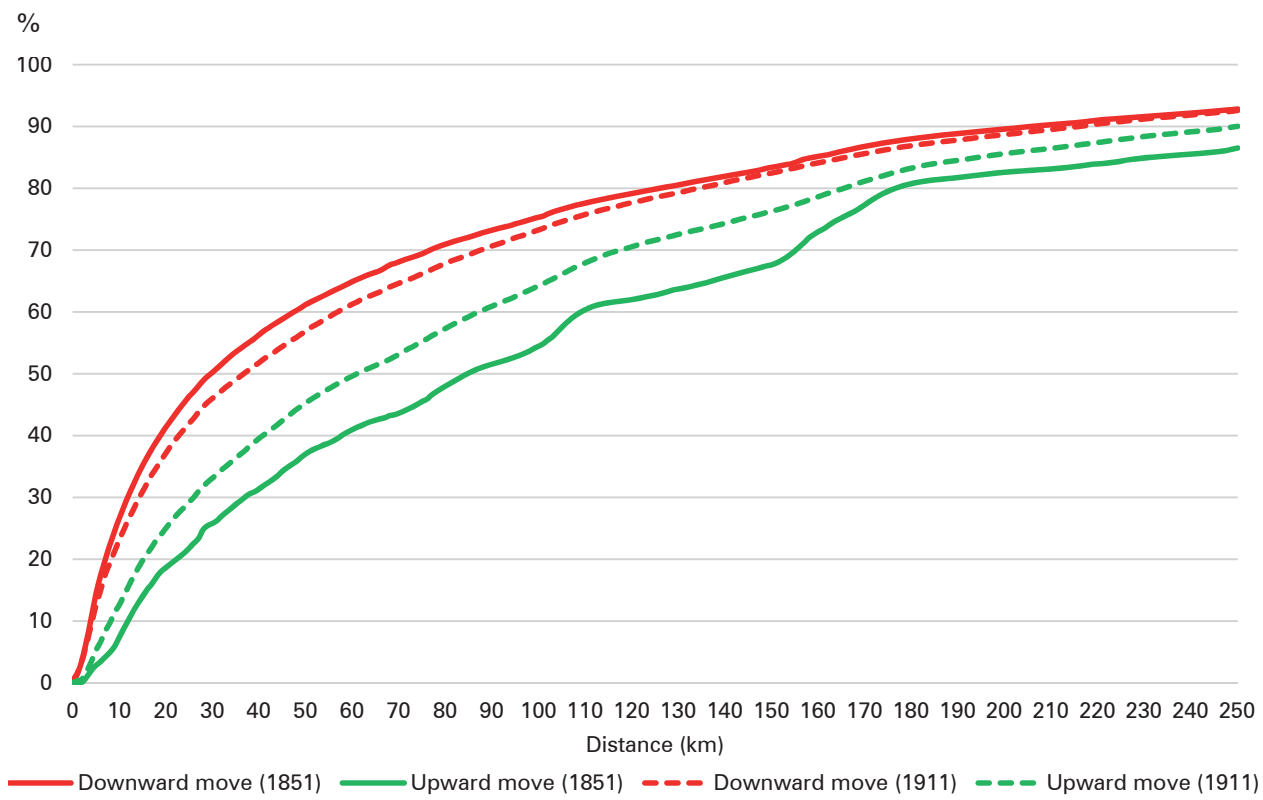

Source: Author's analysis based on data from UK Data Service SN 7481 (Schürer 2019)

the distances necessary to travel to towns and cities, half of the urban-born migrating down the urban hierarchy travelled less than $30 \mathrm{~km}$ in 1851, the median distance travelled by those moving up being $90 \mathrm{~km}$. In a step-migration model, moves up the urban hierarchy are interpreted as upward social mobility in the absence of recordlinked data. However, were migrants being positively or negatively selected (Long 2005) depending on whether they moved up or down the urban hierarchy? If highly skilled migrants were moving down the urban hierarchy to escape urban disamenities or take a promotion - clergymen migrating to the countryside to become parish priests for example - it would be disingenuous to describe them as downwardly mobile, as it would have represented a gainful move. Figure 16 however, demonstrates that this was not the case, by comparing HiS-CAM scores of individuals migrating both up and down the urban hierarchy by the distance migrated. HiS-CAM scores measure social interaction and as such, are used as a means to stratify occupations from the highest to the lowest social class.

As HiS-CAM is measured on a continuous scale, it is a useful means to quickly identify the relationship between skilled/unskilled occupations and migration. The original scales were constructed from the social interactions derived from marriage registers in Belgium, Britain, Canada, France, Germany, the Netherlands, and Sweden; the "distance" between occupations being estimated from the number of butchers that married the daughters of bakers, for example. These distances were transformed and standardised onto a hierarchical scale between 0 and 100 where 
Fig. 16: Age-standardised HiS-CAM scores of male migrants moving up vs. down the urban hierarchy relative to non-migrants, England and Wales 1851-1911

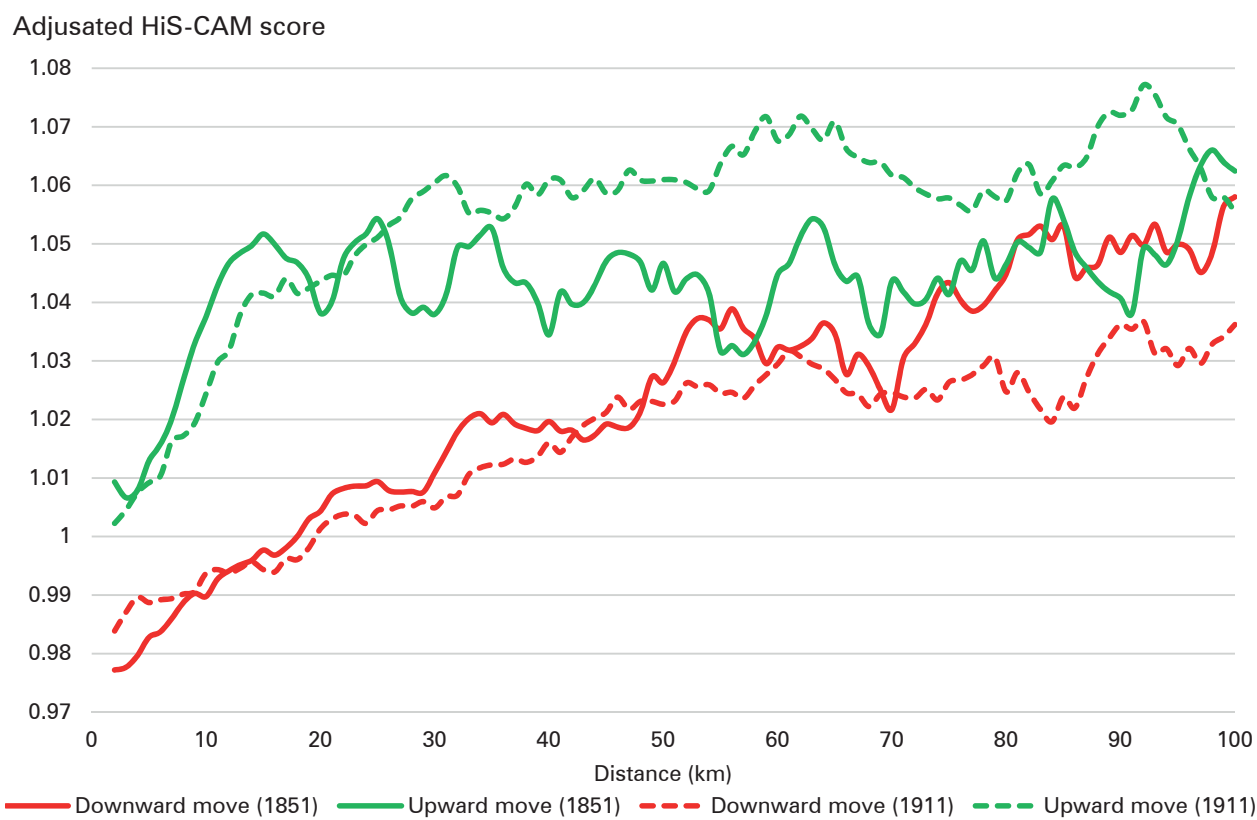

Source: Author's analysis based on data from UK Data Service SN 7481 (Schürer 2019); HIS-CAM for Early Period, 1800 - c. 1890 (used for 1851 census data) and HIS-CAM for Late Period, c. 1890 - c.1938 (used for 1911 census data). Version 1.3.1.E/L [http://www.camsis.stir.ac.uk/hiscam, November 2019]

50 was the mean. The scales used on the 1851 and 1911 census data in figure 16 are the "early" and "late" series respectively, as when these scales are applied to individuals' occupations, it produced a normal distribution around a mean of 50, indicating that the occupational stratification in England and Wales in this period is captured by these scales (Lambert et al. 2013; Prandy/Bottero 2000; Prandy/Lambert 2003; Stewart et al. 1973, 1980; van Leeuwen et al. 2002). The HiS-CAM scores were adjusted further, and figure 16 shows the HiS-CAM scores of migrants as a proportion of the HiS-CAM score of those that stayed in their place of birth. Therefore, scores above/below 1 show migrants were more/less skilled than average in their RSD of birth. However, as the age profile of migrants has been shown to be very different to the population at large, HiS-CAM scores were age-standardised to remove the distorting effect of age.

Figure 16 shows that migrants moving up the urban hierarchy in both 1851 and 1911 made immediate gains compared to those that remained in their hometown. Those that had moved to a larger town or city just $5 \mathrm{~km}$ away had higher HiS-CAM scores than their counterparts who stayed. For men in both 1851 and 1911, migrating $25 \mathrm{~km}$ from their place of birth produced a HiS-CAM score that was around 5 percent higher than those still in their hometown. By contrast, men that moved 
Fig. 17: Proportion of the urban-born population migrating across the urban hierarchy upon leaving service, England and Wales 1851-1911

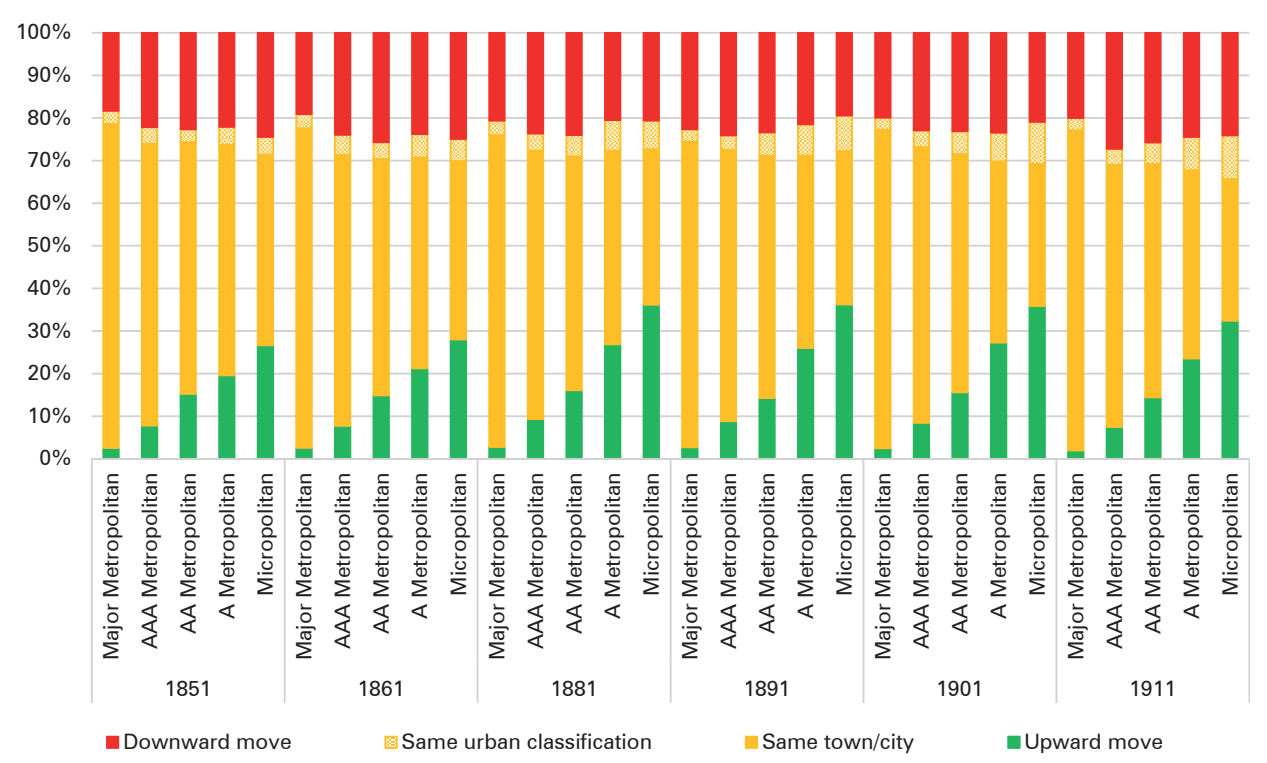

Source: Author's analysis based on data from UK Data Service SN 7481 (Schürer 2019)

less than $20 \mathrm{~km}$ down the urban hierarchy had lower HiS-CAM scores than their counterparts that did not leave their place of birth. This suggests that while migrants that moved even a short distance to a larger town or city were more skilled, those that moved a short distance down the urban hierarchy - likely to outlying districts of the conurbation - did not primarily consist of skilled professionals looking to escape urban disamenities, but were instead the less skilled (Williamson 1981). After $20 \mathrm{~km}$, migrants travelling down the urban hierarchy made gains relative to the stayers, although these gains were less than those made by migrants going up the urban hierarchy.

Whereas step-migration implies that migration continuously moves individuals up the urban hierarchy given the opportunities in ever-larger towns, figure $16 \mathrm{dem}$ onstrates that individuals migrated wherever there were opportunities, leading to what may have appeared to Anderson (1971) to have been "random" moves. What is clear however is that urbanisation was not a consequence of both rural- and urbanborn migrants flowing up the urban hierarchy like "a cistern of water after the tap has been turned on" as Ravenstein (1889) put it, but a function of the rural-born alone migrating to towns and cities in their first - and often only - move.

Although at the national-level, urban-born migrants were making a net move down the urban hierarchy rather than up it, figure 17 shows that the propensity to move down was not uniform across the whole of the urban hierarchy. Despite migrants from towns such as Bury St Edmunds having a greater capacity to move up the urban hierarchy compared to migrants from "major metropolitans" such as Manchester - who could only migrate up the urban hierarchy by travelling to Lon- 
don - it is telling that migrants from Bury St Edmunds were still more likely to move down the urban hierarchy rather than up it. Only those from the smallest urban "micropolitan" settlements were more likely to move up the urban hierarchy -35 percent - rather than down - 20 percent. However, if a net move of 15 percent up the urban hierarchy by those that accounted for just 20 percent of the urban population is evidence of step migration, it is scant evidence indeed.

This paper has so far utilised age-specific and cohort analyses to identify evidence of step-migration up to the point of marriage. Therefore, in the final part of this paper, section six reconstructs mothers' migration paths from the birthplaces of their co-resident children to create a pseudo-longitudinal study to search for evidence of step-migration beyond the moment of marriage.

\section{$6 \quad$ Mother's migration paths}

As it is not possible to match mothers to children that had left home, it would be misleading to analyse mothers' migration paths using the birthplaces of her coresident children if several had already left. It is therefore necessary to identify the cohort most likely to have been co-resident with all her surviving children. Using the 1911 - so-called "fertility" - census (Garrett et al. 2001), figure 18 compares the number of co-resident children with the number of children ever born. This shows that the number of children born and the number of children co-resident began to diverge - as children left the parental home - when mothers reached around the age of 41 . Therefore, this paper will assume that mothers were still co-resident with all their children when they were aged between 36 and 45 as these ages are within half a standard deviation either side of the peak family size at the mothers' age of 41. Given that the census is decennial, it also makes sense to select a ten-year age cohort. However, it is necessary to confirm that this age group is also appropriate for the 1851-1901 censuses.

Using the 1851-1901 censuses in figure 19 confirms that each census year followed an almost identical pattern. The mean number of co-resident children peaks at around 3.75 when mothers were 41 years old in all census years. The $36-45$ age group is therefore the most appropriate to identify those mothers most likely to be co-resident with all her children. Figure 20 meanwhile visualises the number of children co-resident with their mother between 1851 and 1911. This shows that the modal number between 1851 and 1891 was three or four, declining to two by 1901. Given that the modal number of children resident with mothers aged 36-45 was three across the period and the mean was 3.9, this paper will only consider the 1,143,013 ever-married mothers aged 36-45 between 1851 and 1911 that were coresident with three children.

First then, table 3 outlines the average distances migrated by mothers in this age group from their own birthplace through the subsequent births of each of their three children through to their place of residence on census night. While the average distance migrated went up over time, individuals' first move was clearly the most significant. From the 1851 census, individuals' first move placed them on average 
Fig. 18: Number of children born to/co-resident with mothers, England and Wales 1911

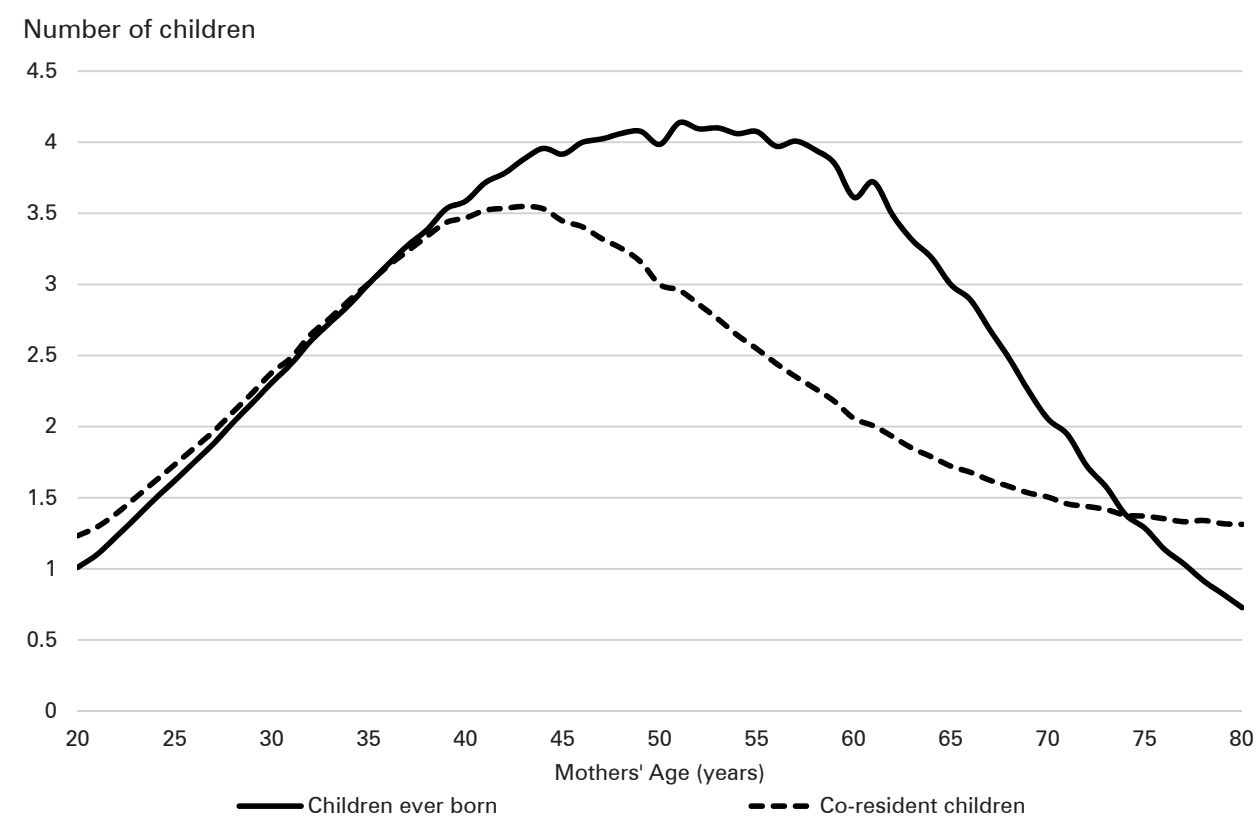

Source: Author's analysis based on data from UK Data Service SN 7481 (Schürer 2019)

Tab. 3: $\quad$ Mean distance $(\mathrm{km})$ migrated between mothers' place of birth and place of residence on census night by way of the birthplaces of her coresident children, England and Wales 1851-1911

\begin{tabular}{lrrrrrrrrrrrr}
\hline Move & \multicolumn{4}{c}{ Av. distance $(\mathrm{km})$ between moves } & \multicolumn{4}{c}{ Av. distance $(\mathrm{km})$ from mothers' birthplace } \\
& 1851 & 1861 & 1881 & 1891 & 1901 & 1911 & 1851 & 1861 & 1881 & 1891 & 1901 & 1911 \\
\hline 1 & 25.8 & 28.8 & 34.0 & 37.5 & 38.1 & 38.9 & 25.8 & 28.8 & 34.0 & 37.5 & 38.1 & 38.9 \\
2 & 7.5 & 9.3 & 11.3 & 11.0 & 9.8 & 10.6 & 27.4 & 30.8 & 36.5 & 39.6 & 40.0 & 40.8 \\
3 & 6.2 & 7.6 & 9.4 & 9.0 & 8.4 & 9.7 & 28.4 & 32.1 & 38.2 & 41.1 & 41.5 & 42.4 \\
4 & 6.9 & 9.0 & 10.2 & 10.5 & 10.5 & 11.7 & 29.3 & 32.6 & 39.5 & 42.5 & 43.3 & 43.7 \\
\hline
\end{tabular}

Note: See text for explanation of the sample. Move 1 refers to the move made between a mothers' own place of birth and the birthplace of her eldest (first) co-resident child. Move 2 is the move between the first and second child and move 3 the move between her second and third child. Move 4 refers to the move that mothers made from the birthplace of her third child to her place of residence as reported on census night.

Source: Author's analysis based on data from UK Data Service SN 7481 (Schürer 2019)

$25.8 \mathrm{~km}$ from their birthplace, rising to $38.9 \mathrm{~km}$ using data from the 1911 census. Subsequent moves were only around a quarter of the distance travelled in the first move and when analysed in conjunction with the distances which these moved placed migrants from their origin, these moves could have been circulating ones, 
Fig. 19: Number of children co-resident with mothers, England and Wales 18511901

Number of children

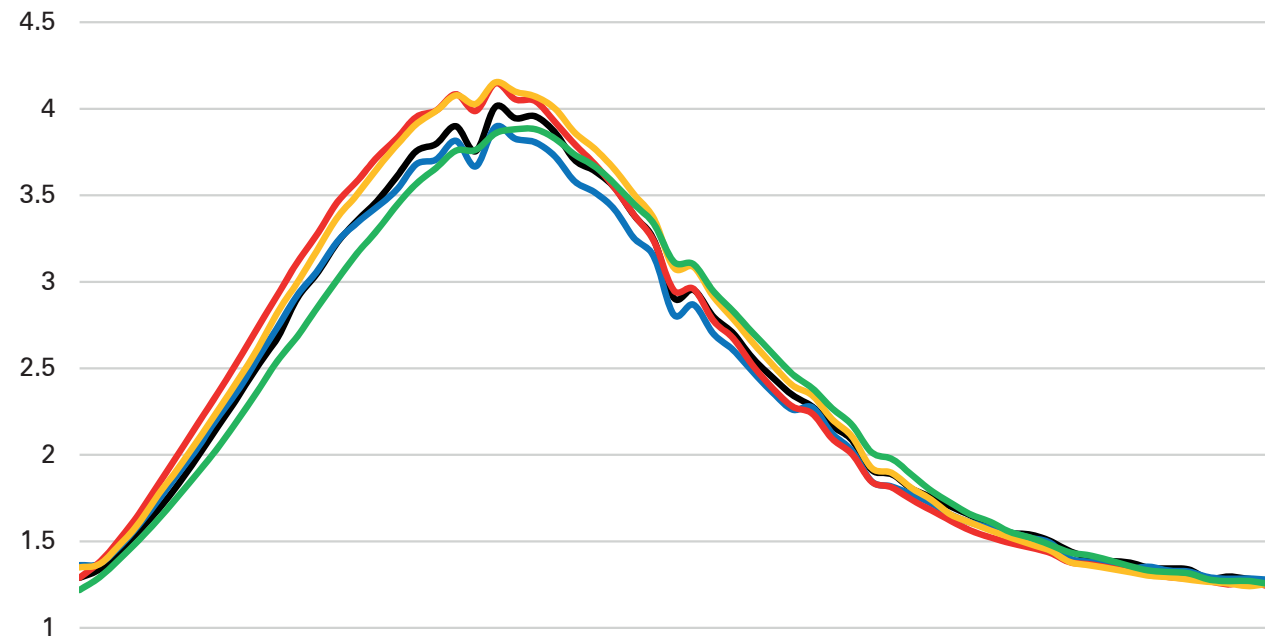

0.5

0

\begin{tabular}{|c|c|c|c|c|c|c|c|c|c|c|}
\hline 20 & 25 & 30 & 35 & 40 & 45 & 50 & 55 & 60 & 65 & 75 \\
\hline
\end{tabular}

Mothers' age (years)

Co-resident children (1851) Co-resident children (1861)

Co-resident children (1891) Co-resident children (1901)

Co-resident children (1881)

Source: Author's analysis based on data from UK Data Service SN 7481 (Schürer 2019)

moving individuals within a locale rather than towards larger and larger settlements in a stepwise fashion (Kussmaul 1981).

For example, in 1891, mothers' fourth move placed them just $5 \mathrm{~km}$ further from their parental home than they were at the birth of their first child, even though between the birth of their first, second and third child they moved 11.0, 9.0 and 10.5 $\mathrm{km}$ respectively. This observation could have been the consequence of one of two phenomena, neither of which suggests step-migration. Either a large number made short-distance moves reminiscent of "circulating" migration (Kussmaul 1981), or there were a few long-distance migrants.

Figure 21 shows it to have been the latter by illustrating the proportion of urbanand rural-born mothers that moved up and down the urban hierarchy. This shows that migratory activity was concentrated prior to the birth of a first child. As this paper is primarily concerned with step-migration and the extent to which migrants continued to move up the urban hierarchy, mothers are deemed to move up/down the urban hierarchy etc. relative to her previous location rather than relative to her birthplace as in previous charts. For example, if a mother was born in a rural settle- 
Fig. 20: Number of children co-resident with an ever-married mother aged 3645, England and Wales 1851-1911

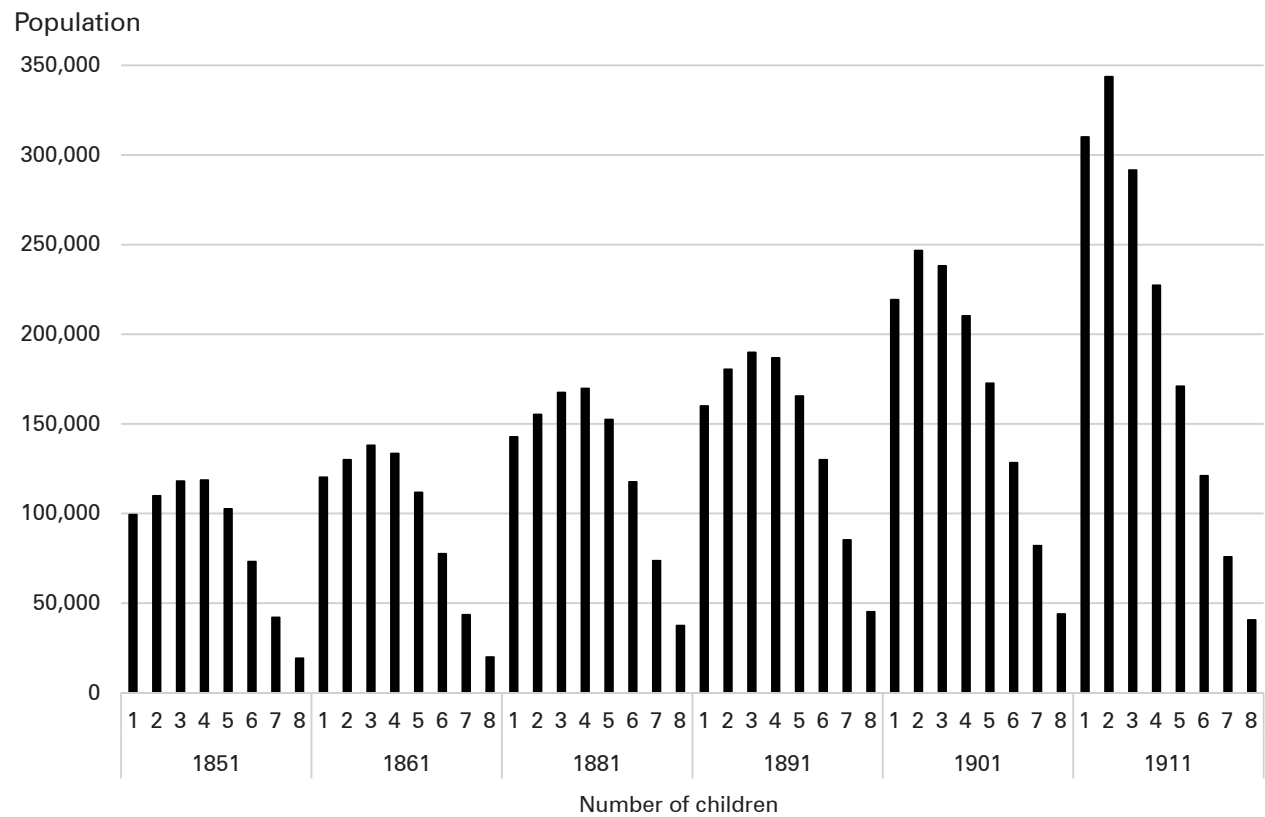

Source: Author's analysis based on data from UK Data Service SN 7481 (Schürer 2019)

ment, gives birth to her first child in London and her second child in Watford, this will be interpreted as an upward first move followed by a downward second move.

Overwhelmingly, both urban- and rural-born mothers were most likely to move up the urban hierarchy in their first move. By 1911, 44.2 percent of rural-born mothers had moved up the urban hierarchy to a town or city while just 7.3 percent did so in their so-called second "move" between the births of their first and second child. Although the urban-born were generally less likely to move up the urban hierarchy, those that did, did so in the first move; 13.9 percent of urban-born mothers moved up the urban hierarchy in their first move in 1911 compared to just 5.3 percent doing so in their second. This compares to 79.2 percent that had not moved settlements between the births of their first and second child. Evidently, the first move that both rural- and urban-born mothers made was the most significant, as it appears to have placed them in their "final" settlement or at least the settlement in which they were resident on census night. In order to demonstrate this more fully, figure 22 shows the proportion of mothers in the sample whose place of residence on census night was either the same as their place of birth or was the result of their first, second, third or fourth move. If a migrants' path was for example; Hemel Hempstead - Watford - London - Watford - Watford, the "final" move to Watford would be deemed to have occurred in the third move rather than in the first move given the intervening move to London. 
Fig. 21: Proportion of mothers migrating across the urban hierarchy between the birthplaces of each co-resident child, England and Wales 1851-1911

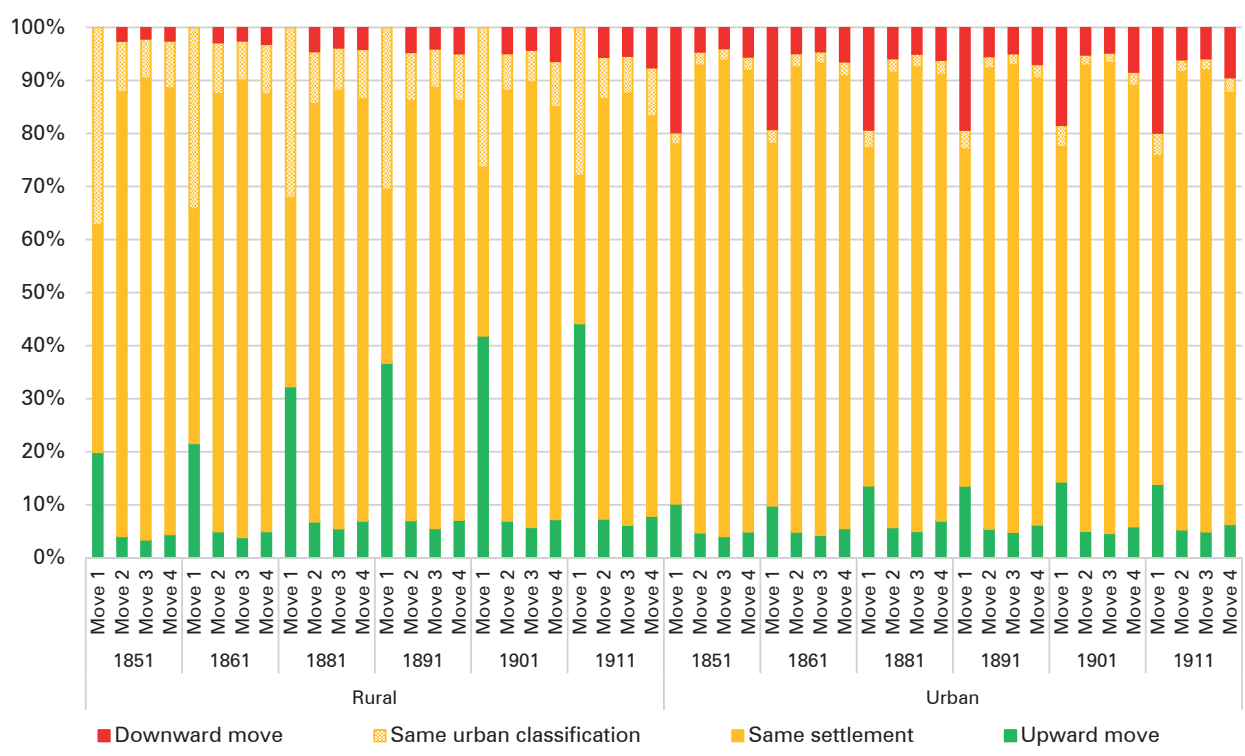

Note: See text for explanation of the sample

Source: Author's analysis based on data from UK Data Service SN 7481 (Schürer 2019)

Figure 22 reinforces the interpretation of figure 21, demonstrating that twothirds of all mothers were in their place of residence on census night either because they were either born there or had made that move prior to the birth of her first child. Although there were some variations in the magnitude of this phenomenon by settlement type, for those that did move, the first move was the most significant across the urban hierarchy. From the 1851 census, 34.1 percent of rural-born mothers made the move to their final destination in their first move compared to the 1911 census, in which 38.5 percent had done so. Although the fourth move also appears to have been important- certainly more so than the second or third move - this may at least in part have been a function of return migration. Even so, it was a less significant determinant of where mothers were resident on census night than the first move. Indeed, the significance of the first move can be further emphasised in figure 23, which measures the proportion of mothers within $x \mathrm{~km}$ of their final destination by the birth of their first child.

Figure 23 shows that the distances that the population were from their "final" destination by the time they had moved to their first destination - the broken lines - had shrunk considerably relative to the distance from their birthplace - the unbroken lines. In 1881 for example, half of mothers were born $8 \mathrm{~km}$ or less from their "final" destination. By the birth of their first child however, half of mothers were within $1 \mathrm{~km}$ of where they were resident on census night. Similarly, three-quarters of all mothers in the sample were born $43 \mathrm{~km}$ or less from where they were enumerated when the census was taken in 1881, but this had shrunk to just $8 \mathrm{~km}$ by 
Fig. 22: Move in which mothers - sorted by birthplace type - migrated to the settlement in which she was resident in census night, England and Wales 1851-1911

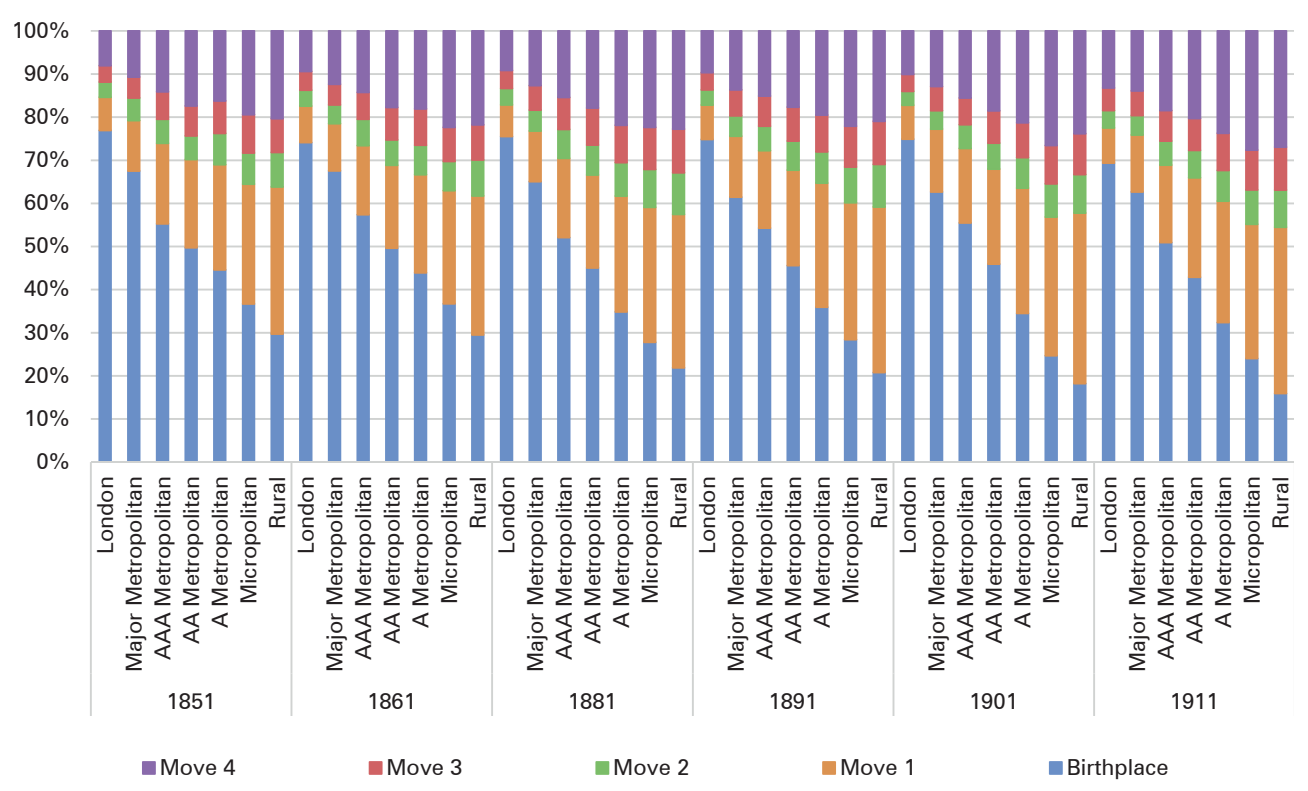

Note: See text for explanation of the sample

Source: Author's analysis based on data from UK Data Service SN 7481 (Schürer 2019)

the time mothers had given birth to their first child. It is therefore evident that on any measure, migrants' first move was by far the most significant and that further moves were the exception rather than the rule.

Having demonstrated that there was little movement post-marriage and that instead the majority of migratory was concentrated in the period prior to the birth of a first child, it seems to be an inescapable conclusion that migration was not stepwise at all, but should instead be characterised as having largely been the product of a single move. The final section summarises these findings.

\section{Conclusion}

This article has attempted to comprehensively demonstrate that step-migration was not the process by which England and Wales urbanised, but instead, migration predominantly occurred in a single step; most commonly at the point of leaving the parental home, but occasionally delayed until leaving service or entering marriage. This finding demonstrates that the census is a more valuable source for the analysis of migration than previously thought, as the moves which historians supposed individuals made between their place of birth and place of residence on census night, did not occur in the majority of cases (Hinde 2004). Returning to the migra- 
Fig. 23: Mothers' distance $(\mathrm{km})$ on census night between a) their own birthplace and $\mathrm{b}$ ) the birthplace of their eldest co-resident child, England and Wales 1851-1911

$\%$

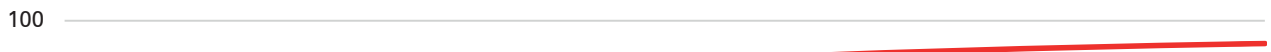
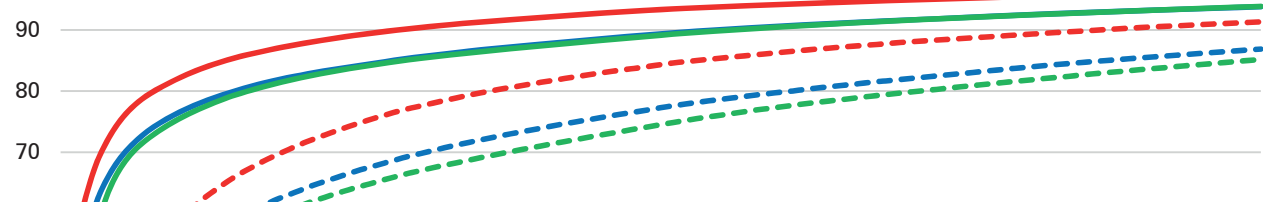

60

50

40

30

20

10

$\begin{array}{lllllllllllllllllllll}0 & 5 & 10 & 15 & 20 & 25 & 30 & 35 & 40 & 45 & 50 & 55 & 60 & 65 & 70 & 75 & 80 & 85 & 90 & 95 & 100\end{array}$

Distance $(\mathrm{km})$

1851 (Distance from birthplace) _ _ _ 1881 (Distance from birthplace)

Note: See text for explanation of the sample

Source: Author's analysis based on data from UK Data Service SN 7481 (Schürer 2019)

tion history of Joseph Shaw, whose dramatic life inspired his son Benjamin to write the family history, does not in hindsight appear to have been more typical - despite having been more interesting - than that of Benjamin, who left home at 21, moved from Dolphinholme to Preston about $30 \mathrm{~km}$ south, and after finding a wife and a job, remained there until his death (Crosby 1991). While such autobiographies, diaries and memoirs should not be ignored, as they are valuable sources which remind us of the daily struggles that the nineteenth-century "precariat" endured, and the decisions required to piece together an existence, the overemphasis on them distorts what the historian perceives to have been the typical experience (Humphries 2010).

Instead, Benjamin Shaw, who left home at an average age, migrated an average distance to an average-sized town and remained in an average job until his death at an average age is just as worthy of our attention. While migration may have been a complex web of interdependent moves for some, this article has argued that while the decision to move may have been complex, requiring individuals to balance a host of competing interests, the decision itself was predominantly expressed as a single transfer, rather than several. For both rural and urban migrants, the majority moved upon leaving home, while those that went into farm service tended to migrate only a very short distance from the parental home initially, delaying their long-distance move until they had left service, at which point many migrated to the towns and cities. Although a minority of females delayed migrating until the point of 
marriage, evidence from moves made by mothers - as reconstructed from the birthplaces of their co-resident children - has shown that as migration did not continue beyond marriage, individuals' moves at the point of marriage did not represent the first "step" of many.

The absence of comprehensive, longitudinal historical data, combined with the appeal of qualitative evidence such as diaries and autobiographies from which migration paths have been reconstructed, (Pooley/D'Cruze 1994) has meant that the typical experience in the historical record is often at odds with the typical experience of the historical actors. In light of this, Ravenstein's stepwise hypothesis made sense. Indeed, limited quantitative evidence allowed Grigg (1977) to point out that the hypothesis would remain untested until the manuscript census returns were analysed. The census has - perhaps rightly - been treated with caution by historians of migration, suspicious that it missed the intermediate moves between individuals' place of birth and their place of residence on census night, which individuals were hypothesised to have made. Although some individuals clearly did move in steps, it does not seem to have been either widespread, or one that was assiduously pursued as a strategy to move up the urban hierarchy. Rather, by demonstrating that on the whole, individuals did not migrate in steps, this article has shown that the step-migration hypothesis should yield to the single-step hypothesis in which the majority of migrants make a single move in their lifetime. It is hoped that this finding restores the faith of migration historians in the value of the manuscript census returns for reconstructing complete migration paths, without the need for laborious and time-consuming record-linkage.

\section{Acknowledgements}

My thanks go to all my colleagues at the Cambridge Group for the History of Population and Social Structure for their advice and ideas offered both informally and at more formal seminars while this paper was in progress. Special thanks go to Romola Davenport who offered useful feedback and insights which I'm sure would have otherwise escaped me, as well as to Kevin Schürer with whom I worked closely while preparing the data analysed here. Thanks also go to Special Issue Guest Editors Philip Rees and Nikola Sander for accepting this contribution and to Philip and two anonymous referees for their constructive and insightful comments and advice. This research is funded by the Economic and Social Research Council project "Migration, urbanisation and socio-economic change, England and Wales 1851-1911". Any errors and omissions that remain are, however, entirely the author's own. 


\section{References}

Anderson, Michael 1971: Urban migration in nineteenth century Lancashire; some insights into two competing hypotheses. In: Annales de Démographie Historique: 13-26

Baines, Dudley 1986: Migration in a mature economy: Emigration and Internal Migration in England and Wales 1861-1900. Cambridge: Cambridge University Press [doi: 10.1017/S0268416000000886].

Bowley, Arthur Lyon 1914: Rural population in England and Wales: a study of the changes of density, occupations and ages. In: Journal of the Royal Statistical Society 77,6: 597-645 [doi: 10.2307/2340305].

Champion, Tony 2019: Updating Ravenstein: Internal Migration as a Driver of Regional Population Changes in the Wider South East of England. In: Comparative Population Studies 44: 269-290 [doi: 10.12765/CPoS-2020-05en].

Conway, Dennis 1980: Stepwise Migration: Toward a Clarification of the Mechanism. In: International Migration Review 14,1: 3-14 [doi: 10.1177/019791838001400101].

Crosby, Alan G. (Ed.) 1991: The Family Records of Benjamin Shaw, Mechanic of Dent, Dolphinholme and Preston: 1772-1841. Chester: The Record Society of Lancashire and Cheshire

Day, Joseph 2018: Leaving home in 19th century England and Wales: A spatial analysis. In: Demographic Research 39,4: 95-135 [doi: 10.4054/DemRes.2018.39.4].

Dennett, Adam; Stillwell, John 2008: Population turnover and churn: Enhancing understanding of internal migration in Britain through measures of stability. In: Population Trends 134: 24-41.

Garrett, Eilidh et al. 2001: Changing Family Size in England and Wales: Place, Class and Demography, 1891-1911. Cambridge: Cambridge University Press.

Grigg, David B. 1977: E. G. Ravenstein and the "laws of migration". In: Journal of Historical Geography 3,1: 41-54 [doi: 10.1016/0305-7488(77)90143-8].

Gritt, Andrew J. 2000: The Census and the Servant: A Reassessment of the Decline and Distribution of Farm Service in Early Nineteenth-Century England. In: Economic History Review 53,1: 84-106 [doi: 10.1111/1468-0289.00153].

Gwynne, Terence; Sill, Michael 1976: Census enumeration: a study of mid-century immigration. In: The Local Historian 12,2: 74-79

Hägerstrand, Torsten 1957: Migration and Area. Survey of a Sample of Swedish Migration Fields and Hypothetical Considerations on their Genesis. In: Hannerberg, David; Hägerstrand, Torsten; Odeving, Bruno (Eds.): Migration in Sweden: A Symposium. Lund: C. W. K. Gleerup: 27-158

Hajnal, John 1953: Age at marriage and proportions marrying. In: Population Studies 7,2: 111-136 [doi: 10.1080/00324728.1953.10415299].

Harvey, Milton E.; Riddell, J. Barry 1975: Development, Urbanization and Migration: A Test of a Hypothesis in the Third World. In: Kosiński, Leszek A.; Prothero, R. Mansell (Eds.): People on the move: Studies on internal migration. London: Methuen: 51-66

Hill, A. B. 1925: Internal migration and its effects upon the death rates with special reference to the County of Essex. Medical Research Council, Special Report Series 95. London: H. M. Stationery Office

Hinde, Andrew 1998: Demographic Methods. London: Arnold

Hinde, Andrew 2004: The use of nineteenth-century census data to investigate local migration. In: Local Population Studies 73: 8-28 
HIS-CAM for Early Period, 1800 - c.1890. Version 1.3.1.E/L [http://www.camsis.stir. ac.uk/hiscam, November 2019].

HIS-CAM for Late Period, c. 1890 - c.1938. Version 1.3.1.E/L [http://www.camsis.stir. ac.uk/hiscam, November 2019].

Holderness, B. A. 1970: Personal mobility in some rural parishes of Yorkshire, 1777-1822. In: Yorkshire Archaeological Journal 42: 444-454.

Hollingsworth, Thomas Henry 1970: Migration: A study based on Scottish experience between 1939 and 1964. Edinburgh: Oliver \& Boyd.

Hudson, John C. 1972: Geographical Diffusion Theory. Evanston: Northwestern University Press.

Hudson, John C. 1975: Some Observations on Migration Theory for an Urban System. In: Kosiński, Leszek A.; Prothero, R. Mansell (Eds.): People on the move: Studies on internal migration. London: Methuen: 67-74.

Humphries, Jane 2010: Childhood and Child Labour in the British Industrial Revolution. Cambridge: Cambridge University Press.

Kussmaul, Ann 1981: Servants in husbandry in early modern England. Cambridge: Cambridge University Press [doi: 10.1017/CBO9780511896002].

Lambert, Paul S. et al. 2013: The construction of HISCAM: A stratification scale based on social interactions for historical comparative research. In: Historical Methods 46,2: 77-89 [doi: 10.1080/01615440.2012.715569].

Llewellyn-Smith, Hubert 1902: Influx of population. In: Booth, Charles: Life and Labour of the People in London. The City of London and the West End, Volume 3. London: Macmillan \& Co: 100-104.

Long, Jason 2005: Rural-Urban Migration and Socioeconomic Mobility in Victorian Britain. In: Journal of Economic History 65,1: 1-35 [doi: 10.1017/S0022050705050011].

Mageean, Deirdre; Pryce, W. T. Rees 1982: Patterns and Processes of Internal Migration. Units 9-10 of D301: Historical Sources and the Social Scientist. Milton Keynes: Open University Press: 6-41.

Mills, Dennis R.; Schürer, Kevin 1996: Migration and population turnover. In: Mills, Dennis R; Schürer, Kevin (Eds.): Local communities in the Victorian census enumerators' books. Oxford: Leopard's Head Press: 218-228.

Newell, Colin 1988: Methods and Models in Demography. London: Belhaven.

Plane, David A.; Henrie, Christopher J.; Perry, Marc J. 2005: Migration Up and Down the Urban Hierarchy and Across the Life Course. In: Proceedings of the National Academy of Sciences 102,43: 15313-15318 [doi: 10.1073/pnas.0507312102]

Pooley, Colin G.; D'Cruze, Shani 1994: Migration and Urbanization in North-West England circa 1760-1830. In: Social History 19,3: 339-358 [doi: 10.1080/03071029408567913].

Prandy, Kenneth; Bottero, Wendy 2000: Social reproduction and mobility in Britain and Ireland in the nineteenth and early twentieth centuries. In: Sociology 34,2: 265-281 [doi: 10.1177/S0038038500000171].

Prandy, Kenneth; Lambert, Paul S. 2003: Marriage, social distance and the social space: an alternative derivation and validation of the Cambridge scale. In: Sociology 37,3: 397-411 [doi: 10.1177/00380385030373001].

Pryor, Robin J. 1969: Laws of Migration? - The Experiences of Malaysia and Other Countries. In: Geographica 5: 65-76. 
Pryor, Robin J. 1975: Migration and the Process of Modernization. In: Kosiński, Leszek A.; Prothero, R. Mansell (Eds.): People on the move: Studies on internal migration. London: Methuen: 23-38.

Ravenstein, Ernst George 1876: The Birthplaces of the People and the Laws of Migration. London: Trübner \& Co.

Ravenstein, Ernst George 1885: The Laws of Migration. In: Journal of the Statistical Society of London 48,2: 167-235 [doi: 10.2307/2979181].

Ravenstein, Ernst George 1889: The Laws of Migration. In: Journal of the Royal Statistical Society 52,2: 241-305 [doi: 10.2307/2979333].

Redford, Arthur 1926: Labour and Migration in England, 1800-1850. Manchester: Manchester University Press.

Satchell, Max; Wrigley, Edward Anthony 2011: Areal data. In: Wrigley, Edward Anthony: The early English censuses. Oxford: Oxford University Press: 122-154.

Saville, John 1957: Rural depopulation in England and Wales, 1851-1951. London: Routledge \& Kegan Paul.

Schürer, Kevin 1989: A note concerning the calculation of the singulate mean age at marriage. In: Local Population Studies 43: 67-70.

Schürer, Kevin 2003: Leaving home in England and Wales 1850-1920. In: van Poppel, Frans; Oris, Michael; Lee, James Z. (Eds.): The road to independence. Leaving home in Eastern and Western societies, 16th-20th centuries. Bern: Peter Lang: 33-84.

Schürer, Kevin; Penkova, Tatiana; Shi, Yanshan 2015: Standardising and Coding Birthplace Strings and Occupational Titles in the British Censuses of 1851 to 1911. In: Historical Methods 48,4: 195-213 [doi: 10.1080/01615440.2015.1010028].

Schürer, Kevin 2019: Integrated Census Microdata (I-CeM), 1851-1911 [data collection] UK Data Service SN 7481.

Skeldon, Ronald 1977: The Evolution of Migration Patterns during Urbanization in Peru. In: Geographical Review 67,4: 394-411 [doi: 10.2307/213624].

Smith, Clifford T. 1951: The movement of population in England and Wales in 1851 and 1861. In: Geographical Journal 117,2: 200-210 [doi: 10.2307/1791657].

Smith, Harry; Bennett, Robert J.; Radicic, Dragana 2018: Towns in Victorian England and Wales: a new classification. In: Urban History 45,4: 568-594 [doi: 10.1017/ S0963926818000020].

Stewart, Alexander; Prandy, Kenneth; Blackburn, Robert M. 1973: Measuring the class structure. In: Nature 245: 415-417 [doi: 10.1038/245415a0].

Stewart, Alexander; Prandy, Kenneth; Blackburn, Robert M. 1980: Social stratification and occupations. London: Macmillan Press.

van Leeuwen, Marco H. D.; Maas, Ineke; Miles, Andrew 2002: HISCO: Historical International Standard Classification of Occupations. Leuven: Leuven University Press.

Williams, Allan M.; Baláž, Vladimir 2012: Migration, risk and uncertainty: theoretical perspectives. In: Population, Space and Place 18,2: 167-180 [doi: 10.1002/psp.663].

Williamson, Jeffrey G. 1981: 'Urban disamenities', dark satanic mills, and the British standard of living debate. In: Journal of Economic History 41,1: 75-83 [doi: 10.1017/ S0022050700042790].

Withers, Charles W. J.; Watson, Alexandra J. 1991: Stepwise migration and Highland migration to Glasgow, 1852-1898. In: Journal of Historical Geography 17,1: 35-55 [doi: 10.1016/0305-7488(91)90004-F]. 
You, Xuesheng 2020: Women's labour force participation in nineteenth-century England and Wales: evidence from the 1881 census enumerators' books. In: Economic History Review 73,1: 106-133 [doi: 10.1111/ehr.12876]:

Zhao, Jiaying; Hahn, Ulrike; Osherson, Daniel 2014: Perception and Identification of Random Events. In: Journal of Experimental Psychology 40,4, 1358-1371 [doi: 10.1037/ a0036816].

\section{Official Papers}

Decennial supplement to registrar-general's Sixty-fifth Annual Report [Part I] BPP 1905 XVIII [Cd.2618] 1-731.

Supplement to registrar-general's Fifty-fifth Annual Report. Pt.I BPP 1895 XXIII Pt [C.7769] 1-738.

Supplement to registrar-general's Seventy-fifth Annual Report. Part III: Registration Summary Tables, 1901-1910 BPP 1914-16 VIII [Cd.8002] 2-747.

Twenty-third Annual report of the registrar-general (1860) BPP 1862 XVII (2977) 196-327.

Dr. Joseph Day ( $₫)$. University of Bristol, School of Geographical Sciences. Bristol, United Kingdom. E-mail: joe.day@bristol.ac.uk

URL: http://www.bristol.ac.uk/geography/people/joseph-day/index.html 


\section{Appendix}

\begin{tabular}{|c|c|c|c|c|c|c|}
\hline Urban Settlement & 1851 & 1861 & 1881 & 1891 & 1901 & 1911 \\
\hline Abercarn & & & & 14364 & 12607 & 16445 \\
\hline Aberdare & 14999 & 32299 & 35533 & 40917 & 43365 & 50830 \\
\hline Abersychan & & & 19906 & 22653 & 17768 & 24656 \\
\hline Accrington & 20063 & 30142 & 48491 & 57769 & 63777 & 67631 \\
\hline Aldershot & & 16720 & 20155 & 16620 & 30974 & 35175 \\
\hline Alfreton & & 11549 & 13885 & 15355 & 17505 & 19046 \\
\hline Altrincham & & & 16050 & 20807 & 30040 & 33298 \\
\hline Annfield Plain & & & & & 11456 & 15007 \\
\hline Arnold & & & & & & 11146 \\
\hline Ashford & & & 9693 & 13962 & 16410 & 13668 \\
\hline Ashington & & & & & 13956 & 24583 \\
\hline Ashton-in-Makerfield & & & & 13379 & 18687 & 21543 \\
\hline Ashton-under-Lyne & 50808 & 53683 & 66732 & 64116 & 77180 & 84395 \\
\hline Atherton & & & 12602 & 15833 & 16211 & 18982 \\
\hline Aylesbury & & & & & & 11048 \\
\hline Bacup & & 24413 & 28261 & 26217 & 22505 & 22318 \\
\hline Banbury & & 10154 & 12127 & 12823 & 12968 & 13523 \\
\hline Bangor & & & & & 11269 & 11236 \\
\hline Barnet & & & & & & 11108 \\
\hline Barnsley & 14913 & 17890 & 29790 & 35427 & 41086 & 50614 \\
\hline Barnstaple & 8667 & 9990 & 11521 & 13613 & 13688 & 14485 \\
\hline Barrow-in-Furness & & & 47259 & 51712 & 57586 & 63770 \\
\hline Barry & & & & 13272 & 27030 & 33763 \\
\hline Basingstoke & & & & & & 11540 \\
\hline Bath & 60286 & 58667 & 60888 & 64462 & 67918 & 70893 \\
\hline Batley & & 14173 & 27505 & 28719 & 36425 & 36389 \\
\hline Bedford & 11693 & 13413 & 22965 & 33237 & 39837 & 44532 \\
\hline Bedlington & & & 14564 & 16996 & 18766 & 25440 \\
\hline Bedwellty & & & & & & 22547 \\
\hline Beeston & & & & & & 11336 \\
\hline Belper & 10082 & & & 10420 & 10934 & 11640 \\
\hline Berwick & 14867 & 13265 & 14599 & 13377 & 13437 & 13075 \\
\hline Beverley & & & 11455 & 12595 & 13183 & 13704 \\
\hline Bexhill & & & & & 12213 & 15330 \\
\hline Bexley & & & & 10605 & 12918 & 15895 \\
\hline Bilston & 23527 & 24364 & 22730 & 23453 & 24034 & 25681 \\
\hline Bingley & & & & 19284 & 15382 & 15801 \\
\hline Birmingham \& Smethwick & 258920 & 356572 & 570002 & 663864 & 813861 & 911097 \\
\hline Bishop Auckland & & & 12246 & 15400 & 15477 & 20746 \\
\hline Blackburn & 50552 & 73300 & 106910 & 125193 & 131328 & 133052 \\
\hline Blackpool & & & 12711 & 24637 & 48608 & 60138 \\
\hline Blaenavon & & & & 8499 & 10869 & 12010 \\
\hline Blaydon & & & 9073 & 11178 & 20148 & 31015 \\
\hline
\end{tabular}




\section{Appendix: Continuation}

\begin{tabular}{|c|c|c|c|c|c|c|}
\hline Urban Settlement & 1851 & 1861 & 1881 & 1891 & 1901 & 1911 \\
\hline Blyth & & & 12834 & 16710 & 23351 & 28280 \\
\hline Bolsover & & & & & & 11214 \\
\hline Bolton & 71000 & 83024 & 116431 & 142005 & 168215 & 180851 \\
\hline Boston & 16662 & 14712 & 14937 & 17593 & 15667 & 16673 \\
\hline Bournemouth \& Poole & & & 28635 & 61512 & 59451 & 87611 \\
\hline Bradford & 125584 & 129922 & 215556 & 223604 & 260863 & 267769 \\
\hline Brandon \& Byshottles & & & & & 15573 & 17667 \\
\hline Bridgwater & 10960 & 12107 & 12704 & 13341 & 15209 & 16802 \\
\hline Bridlington & & & & & 12482 & 14868 \\
\hline Brierley Hill & & 34257 & 35767 & 36411 & 12042 & 12263 \\
\hline Brighouse & & & 20699 & 27125 & 21735 & 20460 \\
\hline Brighton \& Hove & 69673 & 87317 & 132295 & 148768 & 167222 & 179864 \\
\hline Bristol & 149913 & 169245 & 262501 & 296786 & 352514 & 373012 \\
\hline Brownhills & & & 2040 & 6525 & 12386 & 12921 \\
\hline Burnley & 27042 & 37984 & 63777 & 86480 & 97439 & 109364 \\
\hline Burslem & 19725 & 22327 & 28249 & 32767 & 47048 & 49361 \\
\hline Burton-on-Trent & & 14351 & 39407 & 46212 & 50386 & 48266 \\
\hline Bury & 25077 & 23554 & 51219 & 62320 & 58029 & 58648 \\
\hline Bury St Edmunds & 13900 & 13318 & 16111 & 16630 & 16255 & 16785 \\
\hline Buxton & & & & & 13150 & 14138 \\
\hline Caernarvon & & & 11995 & & & \\
\hline Caerphilly & & & & & 15835 & 32844 \\
\hline Camberley & & & & & & 13673 \\
\hline Camborne & 12887 & 14056 & 13601 & 14700 & 14726 & 15829 \\
\hline Cambridge & 30631 & 28743 & 40896 & 44358 & 51738 & 57007 \\
\hline Cannock & & & 17125 & 20613 & 23974 & 28586 \\
\hline Canterbury & 18142 & 20457 & 21413 & 22301 & 24505 & 24809 \\
\hline Cardiff & 18777 & 39539 & 85914 & 133416 & 170110 & 191401 \\
\hline Carlisle & 25142 & 30632 & 39328 & 42035 & 49477 & 50767 \\
\hline Carlton & & & & & 10041 & 15581 \\
\hline Carmarthen & 10171 & & 10514 & 10338 & 10025 & 10221 \\
\hline Castleford & & & 10530 & 14143 & 17386 & 23090 \\
\hline Caterham & & & & & & 10841 \\
\hline Chelmsford & & & & 11008 & 14888 & 18008 \\
\hline Cheltenham & 40374 & 45659 & 51423 & 50464 & 53245 & 53437 \\
\hline Chertsey & & & & 11397 & 12762 & 13816 \\
\hline Cheshunt & & & & & 12292 & 12954 \\
\hline Chester & 26787 & 32391 & 40839 & 42666 & 45952 & 48369 \\
\hline Chesterfield & 11426 & 15845 & 24764 & 34275 & 27185 & 47647 \\
\hline Chester-le-Street & & & & & 11753 & 14712 \\
\hline Chichester & & & & 11357 & 12244 & 12591 \\
\hline Chorley & 12684 & 15013 & 19478 & 23087 & 26852 & 30315 \\
\hline Cleator Moor & & & 10420 & & & \\
\hline
\end{tabular}




\section{Appendix: Continuation}

\begin{tabular}{|c|c|c|c|c|c|c|}
\hline Urban Settlement & 1851 & 1861 & 1881 & 1891 & 1901 & 1911 \\
\hline Cleckheaton & & & 10653 & 11826 & 12524 & 12866 \\
\hline Clitheroe & & & 10192 & 10828 & 11414 & 12500 \\
\hline Coalville & & & & 10613 & 15281 & 18285 \\
\hline Colchester & 19323 & 23697 & 28261 & 34392 & 38373 & 43452 \\
\hline Colne & & & 10313 & 14023 & 23000 & 25689 \\
\hline Colwyn Bay & & & & & & 12630 \\
\hline Congleton & 10520 & 12344 & 11116 & 10744 & 10707 & 11309 \\
\hline Conisbrough & & & & & 11219 & 16119 \\
\hline Consett & & & 12180 & 13330 & 17151 & 19562 \\
\hline Coseley & & & 36574 & 36860 & 38170 & 22834 \\
\hline Coventry & 44018 & 49076 & 52843 & 61801 & 75492 & 115084 \\
\hline Cowes & & & & 14704 & 11848 & 14294 \\
\hline Crewe & & & 27264 & 32926 & 42074 & 46230 \\
\hline Crompton & & & & 12901 & 13427 & 14750 \\
\hline Crook & & & 11096 & 11430 & 11471 & 12308 \\
\hline Dalton-in-Furness & & & 13339 & 13300 & 13020 & 10763 \\
\hline Darlaston & 10590 & 12884 & 13563 & 14422 & 15395 & 17107 \\
\hline Darlington & 11650 & 15848 & 36311 & 39108 & 44511 & 55702 \\
\hline Dartford & & & 14510 & 11962 & 18644 & 23609 \\
\hline Darwen & 11702 & 16492 & 27626 & 31680 & 38212 & 40332 \\
\hline Dawley & & 11013 & & & & \\
\hline Deal & & 10806 & 12809 & 13456 & 15829 & 16642 \\
\hline Denton & & & 12711 & 13993 & 14934 & 16877 \\
\hline Derby & 42884 & 51049 & 83431 & 99313 & 113060 & 123410 \\
\hline Dewsbury & 19108 & 24386 & 40032 & 50067 & 49601 & 53351 \\
\hline Doncaster & 12052 & 17020 & 24868 & 31998 & 39293 & 48455 \\
\hline Dover & 22073 & 25617 & 30836 & 33918 & 43958 & 43645 \\
\hline Dudley & 37962 & 44951 & 46233 & 45724 & 48733 & 51079 \\
\hline Durham & 15249 & 20290 & 18221 & 15003 & 16094 & 19596 \\
\hline East Barnet & & & & & 10094 & 10780 \\
\hline East Retford & & & & 11010 & 12340 & 13385 \\
\hline Eastbourne & & & 21595 & 34278 & 43344 & 51554 \\
\hline Eastleigh & & & & & & 15247 \\
\hline Ebbw Vale & & & 18672 & 3325 & 17401 & 27250 \\
\hline Eccles & & & 25994 & 35826 & 34369 & 41944 \\
\hline Eckington, Mosborough \& Renishaw & & & 11094 & 12357 & 12895 & 12164 \\
\hline Egham & & & & 10187 & 11895 & 12551 \\
\hline Elland & & & & & 10412 & 10676 \\
\hline Ellesmere Port & & & & & & 10253 \\
\hline Enfield & & 12424 & 19104 & 31803 & 42738 & 56338 \\
\hline Epsom & & & & & 10915 & 19156 \\
\hline Erith & & & & 13414 & 25296 & 27750 \\
\hline Eston & & & 14011 & 19823 & 20844 & 29559 \\
\hline
\end{tabular}




\section{Appendix: Continuation}

\begin{tabular}{|c|c|c|c|c|c|c|}
\hline Urban Settlement & 1851 & 1861 & 1881 & 1891 & 1901 & 1911 \\
\hline Exeter & 42011 & 39851 & 48391 & 52094 & 54704 & 59611 \\
\hline Exmouth & & & & & 10485 & 11962 \\
\hline Falmouth & & & 12131 & 14076 & 11789 & 13132 \\
\hline Farnborough & & & & & 11500 & 14199 \\
\hline Farnham & & & & & 6124 & 11321 \\
\hline Farnworth & 10625 & 13723 & 27961 & 31751 & 35143 & 37800 \\
\hline Faversham & & & & 10660 & 11646 & 10806 \\
\hline Featherstone & & & & & 9817 & 11543 \\
\hline Fenton & & & 14136 & 17325 & 22742 & 25626 \\
\hline Ferryhill & & & & & & 11822 \\
\hline Fleetwood & & & & & 12082 & 15875 \\
\hline Folkestone & & 9674 & 19297 & 30293 & 39764 & 43446 \\
\hline Friern Barnet & & & & & 11566 & 14924 \\
\hline Frome & 11916 & 11200 & 11181 & 11464 & 11057 & 10901 \\
\hline Gainsborough & & & 10979 & 14594 & 17660 & 20587 \\
\hline Gelligaer & & & & & 17242 & 35521 \\
\hline Glossop & 13414 & 14785 & 23550 & 24557 & 21526 & 21688 \\
\hline Gloucester & 24490 & 26175 & 37464 & 41689 & 47955 & 50035 \\
\hline Goole & & & 11187 & 15735 & 16576 & 20684 \\
\hline Grantham & 10870 & 11116 & 16210 & 17062 & 18313 & 20070 \\
\hline Gravesend & 21782 & 24626 & 32092 & 36094 & 40102 & 43534 \\
\hline Grays, Thurrock & & & & 12219 & 13834 & 15998 \\
\hline Great Harwood & & & & & 12015 & 13815 \\
\hline Great Yarmouth & 30879 & 34810 & 46159 & 48734 & 50704 & 55905 \\
\hline Grimsby & & 11067 & 42963 & 56364 & 75716 & 96076 \\
\hline Guildford & & & 11645 & 18155 & 20400 & 23820 \\
\hline Halifax & 54682 & 59860 & 87130 & 101823 & 104936 & 101553 \\
\hline Hanley & 10573 & 33009 & 54285 & 62147 & 61599 & 66255 \\
\hline Harrogate & & & 11826 & 14691 & 28423 & 35666 \\
\hline Harrow & & & & & 16121 & 28997 \\
\hline Hartlepool & 13511 & 25876 & 45256 & 62532 & 82270 & 84567 \\
\hline Harwich & & & & & 10070 & 13622 \\
\hline Haslingden & & 10109 & 14298 & 16030 & 18543 & 18719 \\
\hline Hastings & 16753 & 23375 & 44858 & 56225 & 65528 & 61145 \\
\hline Heanor & & & & & 12418 & 15289 \\
\hline Hebburn \& Jarrow & & & 37719 & 50858 & 20901 & 21763 \\
\hline Heckmondwike & 11514 & 14520 & 22039 & 23377 & 23439 & 23674 \\
\hline Hemel Hempstead & & & & & 11264 & 12888 \\
\hline Hemsworth & & & & & & 10173 \\
\hline Hereford & 11285 & 14065 & 17173 & 20122 & 21382 & 22568 \\
\hline Hertford & & & & & & 10383 \\
\hline Hetton-le-Hole & & & 11000 & 12757 & 13673 & 15678 \\
\hline Heywood & 13526 & 17248 & 22582 & 21037 & 25458 & 26697 \\
\hline
\end{tabular}




\section{Appendix: Continuation}

\begin{tabular}{|c|c|c|c|c|c|c|}
\hline Urban Settlement & 1851 & 1861 & 1881 & 1891 & 1901 & 1911 \\
\hline High Wycombe & & & 8320 & 16409 & 15542 & 20387 \\
\hline Hinckley & & & & & 11304 & 12837 \\
\hline Hindley & & & 14715 & 18973 & 23504 & 24100 \\
\hline Hitchin & & & & & 10788 & 12871 \\
\hline Holyhead & & & & & 10079 & 10636 \\
\hline Horsham & & & & & 9446 & 11314 \\
\hline Horwich & & & & 12850 & 15084 & 16285 \\
\hline Hounslow & 11968 & 15533 & 22727 & 26273 & 30863 & 43313 \\
\hline Hoylake \& West Kirby & & & & & 11210 & 14029 \\
\hline Hoyland Nether & & & & 11006 & 12464 & 14638 \\
\hline Hucknall & & & 10023 & 13094 & 15250 & 15870 \\
\hline Huddersfield & 64013 & 72250 & 99369 & 111194 & 111187 & 121055 \\
\hline Hyde & 24038 & 24811 & 29737 & 31682 & 32766 & 33437 \\
\hline Ilkeston & & & 14122 & 19744 & 25384 & 31657 \\
\hline Ipswich & 31869 & 36991 & 49360 & 56012 & 64898 & 73932 \\
\hline Jarrow & & & & & 34295 & 33726 \\
\hline Keighley & 18259 & 18819 & 30395 & 36176 & 41564 & 43487 \\
\hline Kendal & 11829 & 12029 & 14280 & 14896 & 14183 & 14451 \\
\hline Kettering & & & 11095 & 19454 & 28653 & 29972 \\
\hline Kidderminster & 20852 & 13979 & 22299 & 28922 & 27745 & 27336 \\
\hline King's Lynn & 19355 & 16701 & 18539 & 18360 & 20288 & 20201 \\
\hline Kingston-upon-Hull & 85742 & 99196 & 164051 & 205187 & 239886 & 279245 \\
\hline Kingston-upon-Thames & 12290 & 20721 & 35724 & 47217 & 58350 & 68018 \\
\hline Kirkby-in-Ashfield & & & & & 10318 & 15378 \\
\hline Lancaster & 15964 & 15880 & 23501 & 31038 & 40329 & 41410 \\
\hline Langley Park & & & & & & 10175 \\
\hline Leeds & 167459 & 192044 & 289641 & 359092 & 430431 & 448655 \\
\hline Leek & & 11047 & 13003 & 14284 & 15484 & 16663 \\
\hline Leicester & 60612 & 68056 & 134323 & 169365 & 211579 & 227222 \\
\hline Leigh & 13707 & 16007 & 21734 & 28708 & 40001 & 44103 \\
\hline Lewes & & & 10815 & 10850 & 11238 & 11066 \\
\hline Lincoln & 17533 & 21090 & 37088 & 41448 & 49450 & 57285 \\
\hline Littleborough & & & 7891 & 8384 & 11166 & 11697 \\
\hline Liverpool \& Birkenhead & 430287 & 541431 & 773109 & 838905 & 980475 & 1092549 \\
\hline Llandudno & & & & & & 10469 \\
\hline Llanelli & & 15470 & 23933 & 28169 & 25617 & 32071 \\
\hline Long Eaton & & & & & 13045 & 19207 \\
\hline Longton & 15149 & 16690 & 32112 & 35453 & 35815 & 37479 \\
\hline Loughborough & 11210 & 10830 & 14746 & 18357 & 21508 & 22990 \\
\hline Louth & 10748 & 10560 & 10691 & 10040 & & \\
\hline Lowestoft & & 10736 & 19696 & 23398 & 33135 & 37886 \\
\hline Luton & 10648 & 15329 & 26140 & 32401 & 36404 & 52220 \\
\hline Lye & & & & 10165 & 10976 & 11684 \\
\hline
\end{tabular}




\section{Appendix: Continuation}

\begin{tabular}{|c|c|c|c|c|c|c|}
\hline Urban Settlement & 1851 & 1861 & 1881 & 1891 & 1901 & 1911 \\
\hline Macclesfield & 41189 & 21493 & 39270 & 37758 & 34624 & 34797 \\
\hline Maesteg & & & & & 15012 & 24977 \\
\hline Maidenhead & & & & 9781 & 12980 & 15219 \\
\hline Maidstone & 20740 & 23016 & 29623 & 33673 & 33516 & 35475 \\
\hline Malden & & & & & & 12137 \\
\hline Malvern & & & & 13391 & 13484 & 13324 \\
\hline Manchester \& Salford & 434525 & 518573 & 699396 & 799844 & 922278 & 1018640 \\
\hline Mansfield & 10667 & 10225 & 13653 & 15925 & 21445 & 36888 \\
\hline Mansfield Woodhouse & & & & & & 11015 \\
\hline Margate & 10099 & 10019 & 18226 & 21367 & 27141 & 30623 \\
\hline Maryport & & & & 13667 & 11897 & 11418 \\
\hline Medway Towns & 45787 & 55541 & 70839 & 88295 & 111679 & 126941 \\
\hline Merthyr Tydfil & 46378 & 49794 & 48861 & 58080 & 69228 & 80990 \\
\hline Mexborough & & & & & 10430 & 14401 \\
\hline Middlesbrough & & 19416 & 63141 & 83709 & 101201 & 109230 \\
\hline Middleton & 12548 & 14482 & 17600 & 19793 & 25178 & 27980 \\
\hline Millom & & & & & 10426 & \\
\hline Mirfield & & & 15872 & 16841 & 11341 & 11712 \\
\hline Morecambe & & & & & 11798 & 12131 \\
\hline Morley & & & 18482 & 18725 & 21623 & 25774 \\
\hline Mossley & & & 2112 & 7278 & 13452 & 13205 \\
\hline Mountain Ash & & & 18652 & 15795 & 30777 & 41881 \\
\hline Nantyglo \& Blaina & & & & & 13489 & 15395 \\
\hline Nantyglo, Blaina \& Abertillery & & & & 25913 & 21945 & 35415 \\
\hline Neath & & & 10347 & 11060 & 13720 & 17586 \\
\hline Nelson & & & 16725 & 31339 & 32816 & 39479 \\
\hline Newark & 11517 & 11676 & 14238 & 14571 & 14992 & 16408 \\
\hline Newburn & & & & & 10437 & 10781 \\
\hline Newbury & & & 10609 & 12957 & 11061 & 12107 \\
\hline Newcastle \& Gateshead & 125817 & 153567 & 240250 & 308979 & 365841 & 422995 \\
\hline Newcastle-under-Lyme & 10290 & 12638 & 17493 & 18425 & 19914 & 20044 \\
\hline Newmarket & & & & & 10688 & 10482 \\
\hline Newport (Isle of Wight) & & & & 12173 & & \\
\hline Newport (Monmouthshire) & 19323 & 24756 & 40456 & 55858 & 67270 & 83691 \\
\hline Newton Abbot & & & & 10951 & 12451 & 13646 \\
\hline Newton-le-Willows & & & 10580 & 12861 & 16699 & 18451 \\
\hline Normanton & & & & 10234 & 12352 & 15032 \\
\hline Northampton & 26657 & 32813 & 59042 & 76921 & 87021 & 86780 \\
\hline Northwich & & 8979 & 13886 & 18129 & 19575 & 20500 \\
\hline Norwich & 68195 & 74440 & 85684 & 100970 & 116162 & 123844 \\
\hline Nottingham & 94463 & 105372 & 186267 & 216756 & 246761 & 259904 \\
\hline Nuneaton & & & & 11580 & 24996 & 37073 \\
\hline Oakengates & & & & 7389 & 10906 & 11744 \\
\hline
\end{tabular}




\section{Appendix: Continuation}

\begin{tabular}{|c|c|c|c|c|c|c|}
\hline Urban Settlement & 1851 & 1861 & 1881 & 1891 & 1901 & 1911 \\
\hline Ogmore & & & & & 19907 & 16217 \\
\hline Oldbury & 11640 & 15703 & 18306 & 22697 & 25191 & 32232 \\
\hline Oldham & 59008 & 79819 & 136154 & 163975 & 165759 & 175782 \\
\hline Ossett & & & 10957 & 10984 & 12903 & 14078 \\
\hline Oxford & 28887 & 30992 & 46289 & 52994 & 57750 & 62424 \\
\hline Padiham & & & & 9923 & 12205 & 13635 \\
\hline Paignton & & & & & & 11241 \\
\hline Panteg & & & & & & 9103 \\
\hline Pembroke & 10522 & 15071 & 13526 & 13925 & 15853 & 15673 \\
\hline Penarth & & & & 11259 & 14228 & 15488 \\
\hline Pendlebury & & & 31947 & 35448 & 29949 & 33502 \\
\hline Penzance & 14622 & 9414 & 15146 & 16639 & 18098 & 19492 \\
\hline Peterborough & & 12008 & 21964 & 26463 & 32315 & 38362 \\
\hline Plymouth & 102184 & 128262 & 140281 & 158197 & 193184 & 211671 \\
\hline Pontefract & & & & & 13136 & 15649 \\
\hline Pontypridd & & & 13368 & 39557 & 32316 & 43211 \\
\hline Poole & & & 12310 & 15438 & 27558 & 38885 \\
\hline Port Talbot & & & 10389 & 12360 & 16567 & 25218 \\
\hline Portland & & & 10061 & & 15199 & 17011 \\
\hline Portsmouth & 89034 & 117481 & 149603 & 184730 & 217017 & 270334 \\
\hline Preston & 69542 & 85298 & 97445 & 111589 & 117291 & 123666 \\
\hline Pudsey & 11603 & 12912 & 15459 & 17037 & 14907 & 14023 \\
\hline Purley & & & & & & 11389 \\
\hline Radcliffe & & & 16267 & 34286 & 25368 & 25692 \\
\hline Ramsbottom & & & 13460 & 15740 & 15920 & 15146 \\
\hline Ramsgate & 14853 & 15152 & 23073 & 25150 & 27733 & 29603 \\
\hline Rawmarsh & & & & 11983 & 14587 & 17185 \\
\hline Rawtenstall & & & 9891 & 10594 & 31053 & 30516 \\
\hline Reading & 21456 & 25045 & 47957 & 63238 & 77721 & 87884 \\
\hline Redcar & & & & & & 10508 \\
\hline Redditch & & & & 10396 & 12835 & 15463 \\
\hline Redruth & 10571 & 11504 & & 10324 & 10451 & 10814 \\
\hline Reigate & & & 18662 & 22641 & 25993 & 28502 \\
\hline Rhondda & & & 45052 & 69685 & 113735 & 152781 \\
\hline Rhymney & & & & & & 11138 \\
\hline Ripley & & & & & 10111 & 11848 \\
\hline Risca & & & & & & 14149 \\
\hline Rochdale & 32260 & 41678 & 77760 & 80317 & 82623 & 91428 \\
\hline Romford & & & & 10722 & 13656 & 16970 \\
\hline Rotherham & 13277 & 19000 & 36111 & 40663 & 54349 & 62483 \\
\hline Rowley Regis & 14249 & 19785 & 27385 & 30791 & 34670 & 37000 \\
\hline Royal Leamington Spa & 15724 & 18768 & 25141 & 26103 & 26888 & 26984 \\
\hline Royal Tunbridge Wells & 10360 & 13601 & 24810 & 31292 & 31549 & 33888 \\
\hline
\end{tabular}


494 - Joseph Day

\section{Appendix: Continuation}

\begin{tabular}{|c|c|c|c|c|c|c|}
\hline Urban Settlement & 1851 & 1861 & 1881 & 1891 & 1901 & 1911 \\
\hline Royton & & & 10582 & 12568 & 14881 & 17069 \\
\hline Rugby & & & & 11262 & 20339 & 26946 \\
\hline Runcorn & & 10063 & 16251 & 21605 & 17729 & 18647 \\
\hline Rushden & & & & & 12453 & 13354 \\
\hline Ryde & & & 17160 & 16885 & 11043 & 10608 \\
\hline Ryhope & & & & & & 11185 \\
\hline Saddleworth & & & 10461 & 13065 & 12320 & 12603 \\
\hline Sale & & & 11241 & 13878 & 17651 & 22278 \\
\hline Salisbury & 11360 & 12065 & 14297 & 17621 & 20871 & 21217 \\
\hline Scarborough & 12915 & 18377 & 30504 & 33776 & 38161 & 37201 \\
\hline Scunthorpe & & & & & 9023 & 15243 \\
\hline Seaham Harbour & & & & & 10163 & 15757 \\
\hline Sedgley & & & & & & 16527 \\
\hline Sheerness & & 15964 & 15658 & 16111 & 18179 & 17487 \\
\hline Sheffield & 132759 & 193555 & 303151 & 357807 & 425105 & 468830 \\
\hline Shildon & & & & & 11759 & 13488 \\
\hline Shipley & & & 28468 & 30505 & 25573 & 27706 \\
\hline Shirebrook & & & & & & 11116 \\
\hline Shotton & & & & & & 12561 \\
\hline Shrewsbury & 21930 & 24569 & 27775 & 26967 & 29053 & 29432 \\
\hline Sittingbourne & & & 12075 & 13515 & 16029 & 15855 \\
\hline Skipton & & & & 10376 & 11986 & 12977 \\
\hline Slough & & & & & 11453 & 14982 \\
\hline South Elmsall & & & & & & 11445 \\
\hline South Shields & 28974 & 35239 & 56875 & 78391 & 102416 & 108647 \\
\hline Southall & & & & & 13200 & 26323 \\
\hline Southampton & 41426 & 53996 & 81014 & 102672 & 122829 & 129270 \\
\hline Southend-on-Sea & & & & 13242 & 33312 & 69035 \\
\hline Southport & & & 42468 & 55413 & 62280 & 69643 \\
\hline Sowerby Bridge & & & & 9172 & 11477 & 11350 \\
\hline Spalding & & & & & & 10308 \\
\hline Spennymoor & & & 13772 & 13948 & 15067 & 14294 \\
\hline St Albans & & & 10876 & 12707 & 17802 & 18133 \\
\hline St Helens & 28042 & 37961 & 56872 & 68628 & 84410 & 96551 \\
\hline Stafford & 10839 & 14358 & 20322 & 21423 & 22749 & 27783 \\
\hline Staleybridge & 11053 & 27907 & 37038 & 38211 & 27673 & 26513 \\
\hline Stanley & & & & 15576 & & 13586 \\
\hline Stapleford & & & & & & 11106 \\
\hline Staveley & & & & & 11420 & 12018 \\
\hline Stockport & 55235 & 59984 & 71359 & 88131 & 102295 & 137420 \\
\hline Stockton-on-Tees & 11931 & 16613 & 52514 & 65342 & 72064 & 76866 \\
\hline Stoke-on-Trent & & 11118 & 17272 & 21621 & 30458 & 36218 \\
\hline Stourbridge & 12284 & 13573 & 15374 & 14891 & 16302 & 17312 \\
\hline
\end{tabular}




\section{Appendix: Continuation}

\begin{tabular}{|c|c|c|c|c|c|c|}
\hline Urban Settlement & 1851 & 1861 & 1881 & 1891 & 1901 & 1911 \\
\hline Stroud & 11006 & 11255 & 13871 & 15020 & 14695 & 14678 \\
\hline Sunderland & 68753 & 87879 & 127751 & 141745 & 158623 & 168056 \\
\hline Sutton & & & 10334 & 13977 & 17223 & 21270 \\
\hline Sutton Coldfield & & & & & 14264 & 20132 \\
\hline Sutton-in-Ashfield & & & & 10562 & 14862 & 21708 \\
\hline Swansea & 35233 & 45039 & 83395 & 98592 & 102702 & 136210 \\
\hline Swindon & & & 19904 & 36233 & 48373 & 54440 \\
\hline Swinton & & & & & 12217 & 13654 \\
\hline Taunton & 15745 & 14750 & 18351 & 18026 & 21087 & 22561 \\
\hline Teddington & & & & 15874 & 14037 & 17847 \\
\hline Tipton & 24872 & 28870 & 30013 & 29314 & 30543 & 31756 \\
\hline Tiverton & 11144 & 10447 & 10462 & 10892 & 10382 & 10205 \\
\hline Todmorden & 17265 & 20287 & 23213 & 24103 & 25418 & 25404 \\
\hline Tonbridge & & & & 17734 & 12736 & 14796 \\
\hline Torquay & 11474 & 19650 & 30737 & 32383 & 33625 & 38771 \\
\hline Tredegar & & & 34685 & 35628 & 18497 & 23601 \\
\hline Trowbridge & 11148 & 10487 & 11394 & 11901 & 11526 & 11815 \\
\hline Truro & 16377 & 17487 & 6294 & 14978 & 11562 & 11325 \\
\hline Tunstall & & 11207 & 29675 & 30883 & 19492 & 22494 \\
\hline Twickenham & & & 12479 & 16027 & 20991 & 29367 \\
\hline Tyldesley & & & & 12891 & 14843 & 15582 \\
\hline Tynemouth & 28799 & 33698 & 45621 & 44968 & 49623 & 58816 \\
\hline Ulverston & & & 10008 & 10015 & 10064 & \\
\hline Urmston & & & & & 10250 & 12757 \\
\hline Uxbridge & & & & & & 10374 \\
\hline Wakefield & 23057 & 24256 & 36923 & 40077 & 48256 & 51511 \\
\hline Wallington & & & & & 15742 & 29893 \\
\hline Wallsend & & & 32873 & 42275 & 34254 & 40734 \\
\hline Walsall & 27626 & 40602 & 64262 & 78377 & 86430 & 92115 \\
\hline Walton-le-Dale & & & & 10556 & 11271 & 12350 \\
\hline Walton-on-Thames & & & & & 10329 & 12856 \\
\hline Warrington & 23342 & 26935 & 45239 & 54909 & 65276 & 79308 \\
\hline Warwick & 10973 & 10589 & 11800 & 11903 & 11889 & 11858 \\
\hline Watford & & & 15507 & 25921 & 29124 & 40939 \\
\hline Wednesbury & 14281 & 21968 & 24566 & 25347 & 26554 & 28103 \\
\hline Wellingborough & & & 13794 & 15068 & 18412 & 19753 \\
\hline Wembley & & & & & & 10696 \\
\hline West Bromwich & 34591 & 41795 & 56295 & 59474 & 65175 & 70735 \\
\hline West Houghton & & & & 11077 & 13339 & 15046 \\
\hline Weston-super-Mare & & & 12884 & 15520 & 19048 & 23235 \\
\hline Weymouth & 10128 & 12038 & 14298 & 15399 & 19843 & 22324 \\
\hline Whickham & & & & & 12852 & 18332 \\
\hline Whitby & 10203 & 11137 & 13659 & 12598 & 11368 & 11139 \\
\hline
\end{tabular}




\section{Appendix: Continuation}

\begin{tabular}{|c|c|c|c|c|c|c|}
\hline Urban Settlement & 1851 & 1861 & 1881 & 1891 & 1901 & 1911 \\
\hline Whitehaven & 19292 & 19535 & 20371 & 19733 & 19219 & 21313 \\
\hline Whitley Bay & & & & & & 11436 \\
\hline Whittington & & & & & & 10344 \\
\hline Whitworth & & & 20844 & & & \\
\hline Widnes & & & 24935 & 30011 & 33280 & 34441 \\
\hline Wigan & 40863 & 52794 & 77963 & 92668 & 103690 & 111186 \\
\hline Willenhall & 11931 & 17256 & 18461 & 19366 & 18515 & 18844 \\
\hline Winchester & 13442 & 14393 & 18668 & 19843 & 21339 & 23878 \\
\hline Windsor \& Eton & 14874 & 15073 & 21111 & 20972 & 23602 & 17759 \\
\hline Wingate & & & & & & 10890 \\
\hline Winsford & & & 10041 & 10440 & 10382 & 10770 \\
\hline Wisbech & 10594 & & & & & 10822 \\
\hline Woking & & & & & 18349 & 24808 \\
\hline Wolverhampton & 49927 & 60860 & 89036 & 97353 & 110150 & 122246 \\
\hline Wolverton & & & & & & 7384 \\
\hline Wombwell & & & & 10942 & 13252 & 17536 \\
\hline Worcester & 27677 & 30561 & 42506 & 43504 & 46624 & 48011 \\
\hline Workington & & & 14361 & 23751 & 26143 & 25065 \\
\hline Worksop & & & 11625 & 12734 & 16112 & 20387 \\
\hline Worsborough & & & & & 10336 & 12750 \\
\hline Worthing & & & 12662 & 17622 & 21735 & 30305 \\
\hline Wrexham & & & 10939 & 12552 & 14966 & 18377 \\
\hline Yeovil & & & & 10943 & 12057 & 13759 \\
\hline York & 35456 & 43791 & 63911 & 70733 & 77914 & 82282 \\
\hline
\end{tabular}

Note: The populations of the towns and cities in this appendix are colour-coded to indicate their position in the urban hierarchy for each census

year. The colours correspond to those used in table 1. For ease of reference:

Major Metropolitan
AAA Metropolitan
AA Metropolitan
A Metropolitan
Micropolitan

See section 2 for the method used to place towns and cities in the urban hierarchy.

Source: Author's calculations using data from Smith et al. 2018 


\section{Comparative Population Studies}

WWW.comparativepopulationstudies.de

ISSN: 1869-8980 (Print) - 1869-8999 (Internet)

\section{Published by}

Prof. Dr. Norbert F. Schneider

Federal Institute for Population Research D-65180 Wiesbaden / Germany

\section{(c) BY-SA}

2019

\section{Managing Editor \\ Prof. Philip Rees \\ Dr. Katrin Schiefer}

\section{Copy Editor}

Julia Luther

\section{Editorial Assistant}

Beatriz Feiler-Fuchs

Wiebke Hamann

\section{Layout \\ Beatriz Feiler-Fuchs \\ E-mail:cpos@bib.bund.de}

\section{Scientific Advisory Board}

Karsten Hank (Cologne)

Michaela Kreyenfeld (Berlin)

Marc Luy (Vienna)

Natalie Nitsche (Vienna)

Peter Preisendörfer (Mainz)

Zsolt Spéder (Budapest)

Rainer Wehrhahn (Kiel)

\section{Board of Reviewers}

Martin Abraham (Erlangen)

Laura Bernardi (Lausanne)

Hansjörg Bucher (Bonn)

Claudia Diehl (Konstanz)

Andreas Diekmann (Zurich)

Gabriele Doblhammer-Reiter (Rostock)

Jürgen Dorbritz (Wiesbaden)

Anette Eva Fasang (Berlin)

E.-Jürgen Flöthmann (Bielefeld)

Alexia Fürnkranz-Prskawetz (Vienna)

Beat Fux (Salzburg)

Joshua Goldstein (Berkeley)

Sonja Haug (Regensburg)

Hill Kulu (Liverpool)

Aart C. Liefbroer (The Hague)

Kurt Lüscher (Konstanz)

Emma Lundholm (Umeå)

Nadja Milewski (Rostock)

Dimiter Philipov (Vienna)

Roland Rau (Rostock)

Tomáš Sobotka (Vienna)

Jeroen Spijker (Barcelona)

Olivier Thévenon (Paris)

Helga de Valk (Brussels)

Heike Trappe (Rostock)

Michael Wagner (Cologne) 